\title{
Combining Swarm Langmuir probe observations, LEO-POD-based and ground-based GNSS receivers and ionosondes for prompt detection of ionospheric earthquake and tsunami signatures: case study of 2015 Chile-Illapel event
}

\author{
Wojciech Jarmołowski ${ }^{1}$, (D), Anna Belehaki $^{5}$ (D), Manuel Hernández Pajares ${ }^{2,3}$ (D), Michael Schmidt ${ }^{4}$, \\ Andreas Goss ${ }^{4}$, Paweł Wielgosz ${ }^{1}$, Heng Yang $^{2}$, Anna Krypiak-Gregorczyk ${ }^{1}$, Ioanna Tsagouri ${ }^{5}$, \\ Evangelos Paouris $^{5}$ (D), Enric Monte-Moreno ${ }^{2}$ (1) Alberto García-Rigo, $^{2,3}$ (D), Beata Milanowska ${ }^{1}$, \\ Eren Erdogan ${ }^{4}$, Victoria Graffigna ${ }^{2}$, and Roger Haagmans ${ }^{6}$ \\ ${ }^{1}$ University of Warmia and Mazury in Olsztyn, Faculty of Geoengineering, ul. Oczapowskiego 2, 10-719 Olsztyn, Poland \\ ${ }^{2}$ Universitat Politecnica de Catalunya, UPC-IonSAT/TALP, 08034 Barcelona, Spain \\ ${ }^{3}$ Institut d'Estudis Espacials de Catalunya (IEEC), 08034 Barcelona, Spain \\ ${ }^{4}$ Deutsches Geodätisches Forschungsinstitut der Technischen Universität München, Arcisstraße 21, 80333 Munich, Germany \\ ${ }^{5}$ National Observatory of Athens, IAASARS, 15236 Penteli, Greece \\ ${ }^{6}$ European Space Agency, ESTEC, Keplerlaan 1, 2201 AZ, Noordwijk, The Netherlands
}

Received 9 April 2021 / Accepted 4 November 2021

\begin{abstract}
The study investigates ionospheric electric field responses to the earthquake (EQ) of magnitude 8.3, and the related seismic activity and tsunami triggered by the mainshock in Chile-Illapel region, at 22:54 UTC, in the evening of September 16, 2015. The work is a wider review of available ground and satellite data and techniques available to detect seismically induced traveling ionospheric disturbances (TID) and irregularities of smaller scale. The data used in the experiment includes several types of ground and satellite observations from low-Earth orbit (LEO) satellites. The number of techniques applied here is also extended and includes spectral analysis of LEO along-track data and composed analysis of ground GNSS data. The timeframe of the analyses is focused on September 16 and 17, 2015 but also extended to several adjacent days, where an enhanced seismic activity has been recorded. Several examples of seismically triggered TIDs are shown, as detected by combined observations from more than one source and applying different methods, including spectral analysis. These disturbances occur before the mainshock, just after, or in time following this large EQ, and can be found in close neighborhood of Chile-Illapel or far away from the epicenter. The objective of the work was to demonstrate an increasing number of available data and techniques, which can be limited when applied alone, but their combination can provide many advantages in the analysis of seismically disturbed ionosphere. The combination of LEO satellite data reaching all regions of the globe with local but dense ground-based GNSS data and ionospheric HF sounders looks promising, especially in view of the nearby availability of CubeSat constellations equipped with instruments for ionosphere sounding. An important conclusion coming from the study is a need for spectral analysis techniques in the processing of LEO along-track data and the requirement of the validation of LEO observations with separate LEO data or ground-based data. A general but key finding refers to the complementarities of different observations of the ionospheric electric field, which is critically important in the case of analyzing ionospheric irregularities in the extended and composed ionosphere, especially if not every sounding direction can successfully find it.
\end{abstract}

Keywords: Traveling Ionospheric Disturbances / Earthquake / Tsunami / Ionosphere / Swarm / LEO satellites

*Corresponding author: wojciech. jarmolowski@uwm.edu.pl 


\section{Introduction - state of the art in detection of seismic ionospheric disturbances}

\subsection{Ground GNSS and ionosonde data in the detection of ionospheric disturbances induced by earthquakes and tsunamis}

The change of the ionosphere related with a seismic event can be observed in the parameters such as: total electron content (TEC), electron density (ED), temperature, ion density, and ion temperature. The atmospheric electric field generated on or near the ground surface during the seismic period is assumed to cause ionospheric anomalies (Pulinets et al. 2000, Pulinets \& Davidenko, 2014). The vertical displacement in the atmosphere, induced by Rayleigh waves, produces an acoustic wave that propagates vertically to the ionosphere by dynamic coupling. During the time of upward propagation, the effect of the conservation of kinetic energy and decreasing of the atmospheric density strongly amplify this acoustic wave. This wave reaches the ionosphere and creates strong variations in the plasma density and plasma velocity. The propagation properties of Rayleigh waves can be estimated by observing the ionosphere, which is shown by Artru et al. (2004). Recently, an increasing number of observations on seismic ionospheric anomalies were reported, and these observations are based on different instrumentations (Jin et al., 2010, 2014; Occhipinti et al., 2013). GNSS is an efficient tool for observing traveling ionospheric disturbances (TID) and determining the 3D distribution of the ionospheric electron density (Liu (Tiger) et al., 2018). The earthquake (EQ) is associated with various electromagnetic signals, which might be detected by GNSS, also as EQ precursors (Ouzounov et al., 2018). The neutral atmospheric parameters and ionospheric TEC can be precisely estimated from ground-based and spaceborne GNSS, as well as by spaceborne GNSS radio occultation observations. The tropospheric and ionospheric delays derived from ground-based GNSS networks, precise orbit determination (POD) GNSS receivers onboard LEO satellites, and spaceborne GNSS Radio Occultation provide a chance to monitor and understand seismic ionospheric disturbances, which may give us a new perspective to observe and forecast the EQs in the future. Komjathy et al. (2012) show that the real-time global TEC monitoring network observing the acoustic and gravity waves generated by the EQ and/or tsunami could give potential warnings. In turn, Garcia et al. (2005) have even proposed a three-dimensional ionospheric tomography for the purpose of TID detection. Applying a complementary method, Maruyama et al. (2011) report tsunami-induced disturbances of the ionosphere by means of the ionosonde stations. Another example of ionosonde application to the analysis of seismically triggered ionosphere disturbances can be found in Liu \& Sun (2011). Both above works refer to the largest $M_{w}=9.1$ Tohoku event, however, Chum et al. (2016) uses ionosonde data as ancillary in the investigation of $M_{w}=7.8 \mathrm{EQ}$ in Nepal 2015.

Co-seismic ionospheric disturbances have been investigated in numerous studies related to the EQs. The example is given in Dučić et al. (2003), who detected TEC perturbations related to the acoustic waves associated with the Rayleigh waves. These disturbances have been measured by GNSS receivers of dense Californian GNSS network following the Denali EQ in 2002. Lognonné et al. (2006) investigated the detection of seismic waves from ground GPS signal and referred to this and other EQs. Recently, more comprehensive studies of seismic ionospheric effects for the 2011 Tohoku-Oki EQ became possible using GNSS observations collected by around 1200 GEONET stations (Liu et al., 2011; Rolland et al., 2011; Tsugawa et al., 2011; Occhipinti et al., 2013). Astafyeva \& Shults (2019) have even applied GEONET to the analysis of EQ source location and have presented possibilities and difficulties of such an approach. The extremely dense ground TEC observations performed by the GEONET network enabled clear distinguishing of acoustic-gravity waves generated at the epicenter, acoustic waves coupled with the Rayleigh wave, and gravity waves coupled with the following tsunami (Occhipinti et al., 2013; Jin et al., 2014; Chou et al., 2020). The southeastward ionospheric disturbances, possibly resulting from the coupling between tsunami and atmosphere, have also been detected (Galvan et al., 2012; Occhipinti et al., 2013). Different propagation velocities, which are related individually to the seismic Rayleigh waves, acoustic waves and tsunami-generated gravity waves were also discussed in several other works (Heki et al., 2006; Jin et al., 2014, 2015; Yang et al., 2019). Thus, we know that TEC disturbances spread out to almost all directions from the epicenter, with the speed of several hundreds of meters to several kilometers per second. Pre-seismic ionospheric anomalies appearing several hours to several days before the main shock have also been reported by lots of researchers as observed in TEC or other ionospheric parameters (Liu et al., 2004; Heki \& Enomoto, 2013, De Santis et al., 2019; Goto et al., 2019, 2006a). Pre-seismic TIDs are often reported in time of the probability of a new EQ precursor. For instance, Liu et al. (2006a) showed changes of GPS TEC anomalies five days before the EQs having a magnitude larger than 5.0. It should be pointed that seismic TIDs have been statistically proved to be dependent on the magnitude and on the focal depth of EQs (Le et al., 2011). EQs with a focal depth of less than $60 \mathrm{~km}$ and magnitude greater than 6.0 provide presumably the major disturbances in ionospheric parameters because such EQ zones at shallower depth have a gigantic amount of energy. Su et al. (2013) reported that for shallow EQs (depth $<40 \mathrm{~km}$ ), the variation of TEC exhibited a significant increase before the EQs.

The relationship between tsunamis and ionospheric disturbances was firstly noticed by Hines (1972), who suggested that the ionospheric signature could be employed as an early warning of the occurrence of a tsunami. The reason for ionospheric signatures of a tsunami is a displacement of the atmosphere on the surface of the sea, which induces atmospheric waves that propagate up to the thermosphere, and subsequently generate amplified perturbations in the ionosphere. Liu et al. (2006b) reported significant theoretical and observational results of tsunami-driven ionospheric signatures caused by the perturbations of TEC after the deadliest Sumatra $M_{w}=9.2$ EQ of 26 December 2004. Artru et al. (2005) used ground GNSS network data and detected small-scale ionospheric disturbances of gravity waves generated by the tsunami. This tsunami was triggered by Peru $M_{w}=8.2$ EQ in 2001 and reached Japan several hours later. These ionospheric disturbances observed above Japan indicated that their time delay after the EQ coincides with the propagation time of the tsunami. 
Savastano et al. (2017) used a number of local GNSS receivers in Hawaii to detect tsunami-induced ionospheric anomalies after $M_{w}=7.7$ Haida-Gwaii EQ in 2012. They had found typical variations in TEC when tsunami-induced ionospheric waves arrived on the islands. Rolland et al. (2010) analyzed perturbed ionospheric signal offshore Hawaii in the same way, using a limited number of receivers, but after three different $\mathrm{EQ} /$ tsunami events. They performed a preliminary spectral analysis of the detected disturbances. A significantly larger number and better spatial distribution of ground GNSS data have been applied by Azeem et al. (2017). They accurately presented the spatiotemporal evolution of TEC perturbations, which came to the USA coast and reached CORS GNSS network $12 \mathrm{~h}$ after Tohoku EQ.

The magnitude of EQ and time of perturbances, as well as their relation with ionospheric response size have been analyzed by Astafyeva et al. (2013). Perevalova et al. (2014) examined the EQs having various magnitudes in different regions of the Earth, and found that there was a threshold magnitude (around $M_{w}=6.5$ ) below which there were no observed seismic TEC disturbances in ground GNSS data. Ke et al. (2016) performed another statistical analysis of seismoionospheric anomalies related to the EQs in China whose magnitude exceeds some selected level. The geomagnetic conditions also significantly influence the amplitude of TID (Heki \& Ping, 2005; Afraimovich et al., 2010). The ionospheric disturbance amplitude is highly relative in disturbed geomagnetic days, and the filtered TEC series is affected by the geomagnetic variations. The coincidence of the tsunami TID source location and the tsunami location shows that the ionospheric TEC recorded by local ground-based GNSS receivers can be used to confirm the tsunami occurrence, find the tsunami location, and support the tsunami early warning (Liu et al., 2020).

\subsection{Low-Earth-Orbit (LEO) satellite data in the detection of ionospheric disturbances induced by earthquakes and tsunamis}

The example of a completed mission designed to monitor the variations in the atmosphere related to the EQs was the French DEMETER (Detection of Electromagnetic Emissions Transmitted from EQ Regions) mission (2004-2009). The scientific payloads on the DEMETER satellite were the Langmuir probe (LP), measuring ED and electron temperature, and the ion analyzer (IAP). Among other payloads, the Electric Field Instrument (fr. ICE) and magnetic search coil instrument (fr. IMSC) were responsible for the determination of the electric and magnetic field variations related to the EQs. DEMETER provided observations of electromagnetic fluctuations related to the EQs (Venkatraman \& Heelis, 2000; Píša et al., 2011; Li \& Parrot, 2013). DEMETER data have also been examined in various ways to define the perturbations of the ionosphere caused by acoustic gravity waves from the EQs (Anagnostopoulos et al., 2012; Píša et al. 2011; Li \& Parrot 2013; Ryu et al. 2014). An extensive, statistical approach to DEMETER data by Parrot and $\mathrm{Li}$ (2018) has shown that significant number of satellite data can be useful in analyzing EQ precursors. It was concluded that a combination of satellite and ground data could be particularly powerful in detections and warnings. The precursory character of TIDs was also reported in the study combining GNSS and DEMETER data by Akhoondzadeh et al. (2010), Zhang et al. (2012), and Ibanga et al. (2018).

The existing missions, including LPs among the scientific payload, are the Swarm constellation (Diego et al., 2019; Luo et al., 2019) and a very recent China Seismo-Electromagnetic Satellite (CSES) (Liu et al., 2019). Swarm is the fifth Earth Explorer mission approved in ESA's Living Planet Program and was successfully launched on November 22, 2013. The research objectives of the Swarm mission are to provide the best-ever survey of the geomagnetic field and electric field in the atmosphere using a constellation of three identical satellites carrying precise magnetometers and electric field instruments. It is very common for EQ-related Swarm studies to incorporate magnetic data obtained from these three satellites. There are published studies of precursory signals in magnetic data (Zhu et al., 2019) and as papers referring to co-seismic disturbances of the magnetic field (Akhoondzadeh, 2019; Marchetti et al., 2020a). However, Swarm's payloads also include LP sensors and POD GPS receivers, and therefore seismic signals in the electric field were also investigated using these data. Stanica et al. (2018) studied jointly the variations of magnetic and electric parameters as precursory to some quite low magnitude EQs. A stronger event was investigated by Marchetti \& Akhoondzadeh (2018), and pre-seismic and co-seismic characteristics in magnetic and ED data were shown. De Santis et al. (2019) prepared a statistical assessment of magnetic and ED disturbances related to $12 \mathrm{EQs}$ with various magnitudes. Pulinets \& Ouzounov (2018) have applied Swarm B ED data for the analysis of Chile-Illapel EQ and have provided preliminary observations of pre-seismic disturbances. Finally, Marchetti et al. (2020b) investigated possible lithosphere-atmosphereionosphere coupling effects prior to the $M_{w}=7.5 \mathrm{EQ}$ using, among others, Swarm and CSES datasets.

The constellation of FORMOSAT-3/COSMIC (Constellation Observing System for Meteorology, Ionosphere, and Climate) satellites has been applied for TID detection in the ionosphere. Coisson et al. (2015) presented the first experimental radio occultation observation of a gravity wave excited by a tsunami during the 2011 Tohoku event. Tulasi Ram et al. (2017) gathered simultaneous observations of ionospheric perturbations from ground-based GPS vertical TEC (VTEC) and COSMIC radio occultation measurements. They also estimated Rayleigh wave velocity by the application of spectral methods to ground GNSS data. Sun (2019), in turn, analyzed ground-based GNSS TEC and ED from FORMOSAT-3/COSMIC and prepared spectral analysis also for the perturbations in COSMIC data. There are also some evidence of the usability of other LEO signals in detecting seismically triggered waves in the ionosphere, mainly in reference to Tohoku 2011, which due to its magnitude, still stands as the most effective case study. Garcia et al. (2014) have presented high-frequency atmospheric density perturbations of GOCE accelerometer and thruster, at the height of $270 \mathrm{~km}$, induced by gravity waves created by the Tohoku-Oki tsunami propagating in the Pacific Ocean. Yang et al. (2014) showed that significant TEC fluctuations could be observed by the K/Ka-band ranging (KBR) signals approximately 20 min after the mainshock of the Tohoku-Oki EQ. At that time, the GRACE satellites were orbiting the Earth at an altitude of $450 \mathrm{~km}$. 
a)

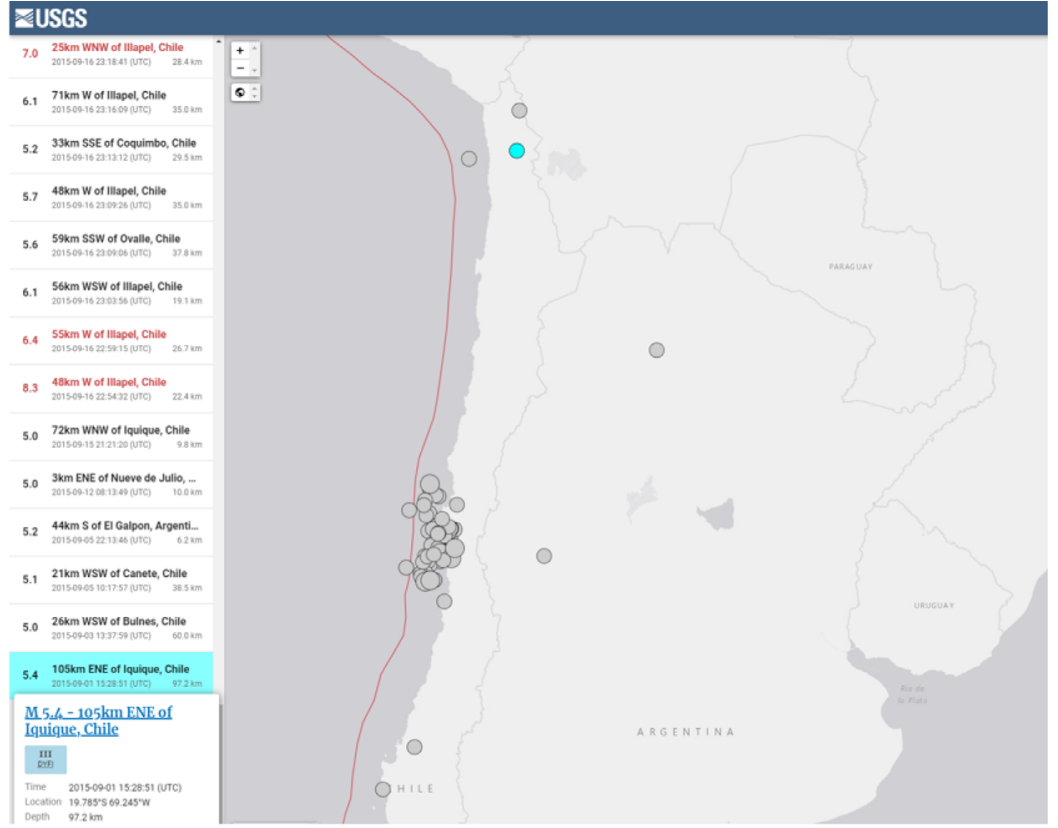

b)

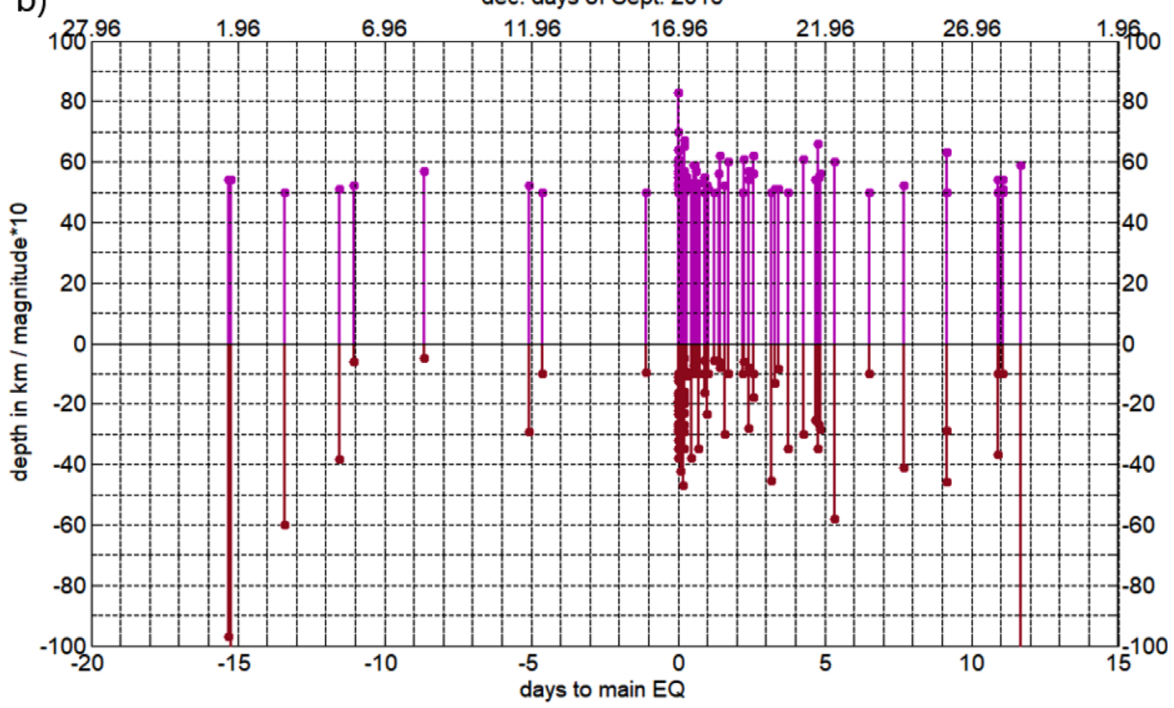

Fig. 1. Seismic activity from magnitude 5.0 in region of South America (close to Chile-Illapel) during September 2015. (a) Map of EQs in September 2015 in the neighborhood of Chile-Illapel. (b) Plot of EQs with respect to mainshock. Magenta stems denote EQ magnitude multiplied by 10 , brown stems denote hypocenter depth. Source of subfigure (a) and data: USGS.

\section{Chile-Illapel earthquake and tsunami of} September 16, 2015: the largest event in time of Swarm, but little explored in the ionosphere from satellite and ground data

\subsection{The characteristics of Chile-Illapel region, earthquake and tsunami}

The largest EQ/tsunami event during the Swarm mission was recorded in Chile. The EQ on September 16 in 2015, occurred at 22:54 UTC. The EQ was located $46 \mathrm{~km}$ offshore from Illapel in Chile, which is also $169 \mathrm{~km}$ northerly from Valparaiso in Chile $\left(31.570^{\circ} \mathrm{S}, 71.654^{\circ} \mathrm{W}, 24.9 \mathrm{~km}\right.$ depth - USGS location). This EQ was preceded by several significant EQs, which have indicated increased seismic activity in the Chilean region before the mainshock (Fig. 1). There were also a significant number of aftershocks that occurred after $M_{w}=8.3 \mathrm{EQ}$, and the strong seismic activity persisted there for five days. In general, Figure 1b presents a number of EQs close to the time of mainshock, which has magnitudes starting from 5.0 and is placed no more than $1000 \mathrm{~km}$ away from Chile-Illapel. All these EQs are, in fact, located along the same subducting edge of the South American and Nazca tectonic plates (see Figs. 1a and 2).

The tsunami had started from the mainshock $\left(M_{w}=8.3\right)$ at 22:54 UTC on September 16, 2015. Its wave is the maximum found among all recorded at tide-gauges by the NOAA 


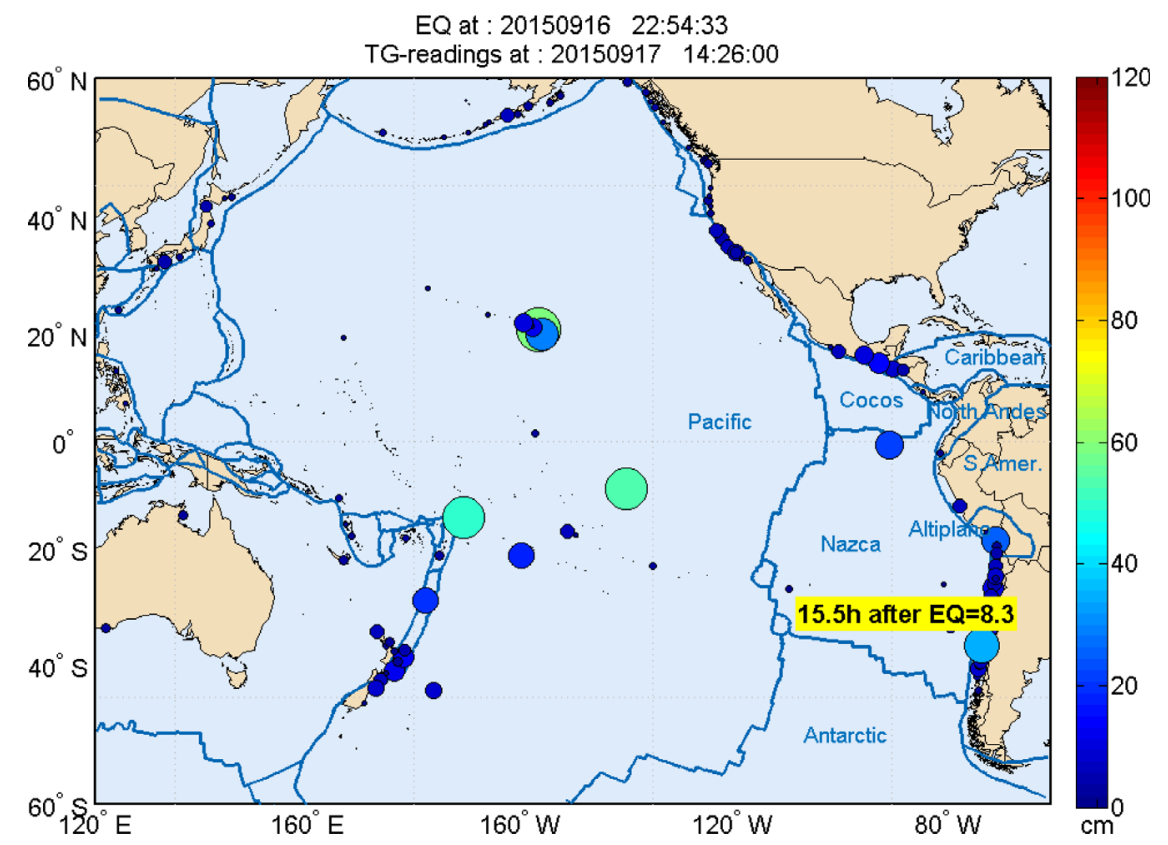

Fig. 2. Residuals from TG and DART readings of Chile Illapel 2015 tsunami (September 16th, 2015) recorded 15.5 h after source EQ.

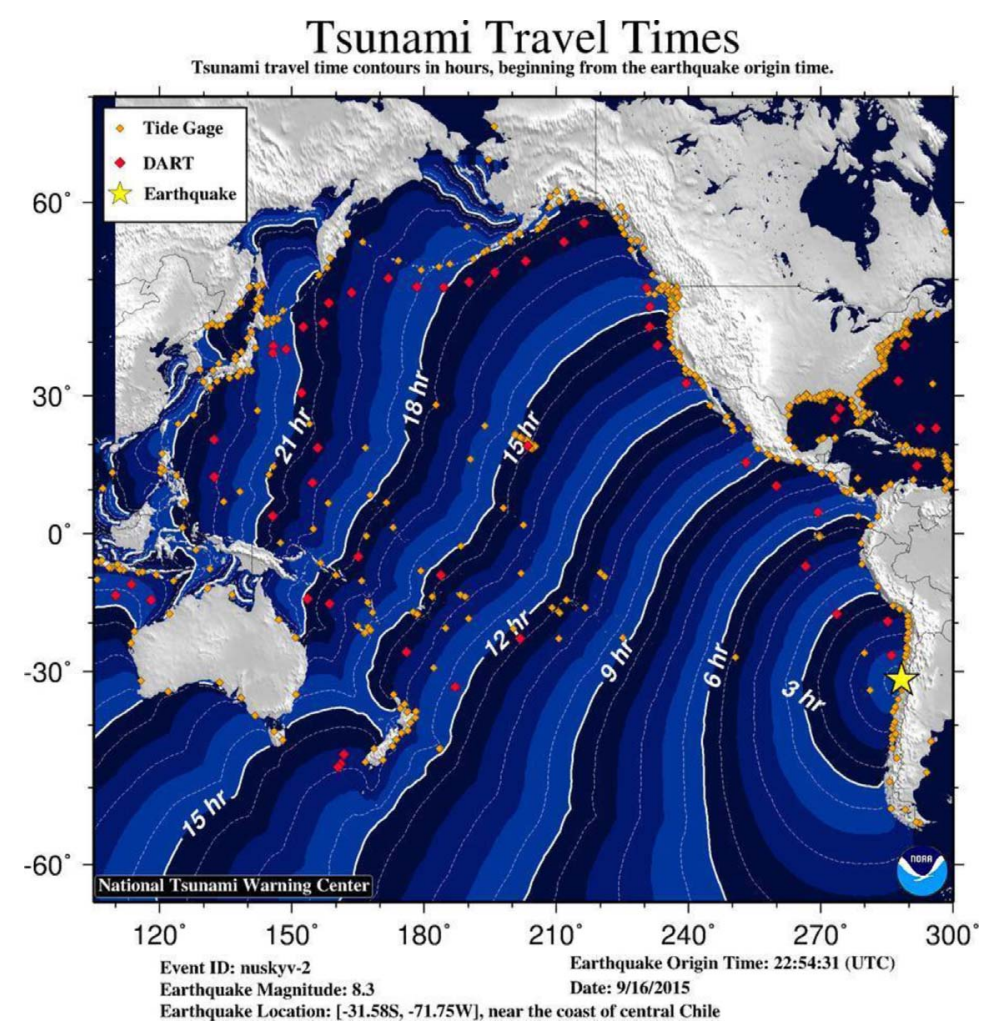

Fig. 3. Travel Time Map of the Chilean 2015 tsunami (September 16th, 2015). Source: NOAA, U.S.TWS: https://www.tsunami.gov/previous. events/?p=09-16-2015-Chile(M8.3).

Tsunami Warning Center, and it reaches $467 \mathrm{~cm}$. Chile-Illapel tsunami event has been recorded at 156 tide-gauges and buoys. Figure 2 presents a snapshot moment of tsunami wave recorded by many tide-gauges in the afternoon of September
17, 2015. The inducing EQ was late in the local evening of the previous day, so the tsunami lasted all day of September 17. The times of arrival of this tsunami can be observed in Figure 3, where we can find that the whole next day 
(September 17, 2015) was necessary for its travel across the Pacific Ocean.

The analyzed Chile region is located at the western border of the South-American tectonic plate, which is rich in a number of smaller, minor plates like the North Andes Plate and Altiplano Plate (Fig. 2). The western edge of the South-American plate is a convergent boundary with the subducting Nazca Plate. The eastward-moving and more dense Nazca Plate is subducting under the South-American Plate, along the Pacific coast, at a rate of $7.7 \mathrm{~cm}$ per year. Altiplano Plate is a small tectonic plate, which was uplifted primarily because of crustal thickening produced by horizontal shortening of a thermally softened lithosphere. Altiplano Plate is located between the Nazca Plate in the southwest (the border is the Atacama Trench) and the South-American Plate that surrounds it from the other sides (Fig. 2).

\subsection{Study objective - the ionosphere above Chile- Illapel EQ/tsunami revisited by Swarm, GRACE, ground GNSS, and ionosondes}

Subsequent to the Tohoku $2011 \mathrm{EQ} /$ tsunami, the ionosphere in the vicinity of the epicenter has been intensively investigated, whereas only single preliminary works focused on the ionospheric responses to Chile-Illapel EQ have been shown. The figures of concentric TIDs after Tohoku appear in many studies (Jin et al., 2014; Yang et al., 2019; Chou et al., 2020). The Chile EQ/tsunami event in 2015 has been investigated notably less frequently than the Tohoku event, also due to the smaller impact on the ionosphere. However, it can be suspected that more sparse GNSS networks in Chile and Argentina can also contribute to this fact. It was quite transparently indicated in Section 1.1 that ground GNSS data, due to several tens of satellites and thousands of stations, are the most encouraging to research on seismic TIDs. This fact comes from one main reason, i.e., ground GNSS networks provide the only reliable spatial view on TIDs and enable to inspect their spatial shapes, spatial relations, and speeds. However, ground GNSS stations have a heterogeneous distribution worldwide, and only a few seismically interesting active zones are rich in dense ground GNSS networks.

Sparse distribution of ground GNSS stations significantly impedes the identification of TIDs in many interesting areas and limits studies on their correlation in a wider range. By means of tens of receivers from the Centro Seismológico Nacional (CSN) and the International GNSS Service (IGS) network, Reddy et al. (2017) report the characteristics of ionospheric perturbations induced by shock acoustic waves of the EQ/tsunami, proving the advantages of GPS observation networks in imaging tsunami-driven ionospheric perturbations. Nevertheless, they strongly limit the area, a number of stations, and GNSS satellites in the analysis, and from their study, it was difficult to discern different velocities of the ionospheric TEC perturbations. Also, the timeframe of their study was limited to the mainshock, which is typical in the studies of seismic ionospheric disturbances. Grawe \& Makela (2017) show ionospheric perturbations appearing in filtered GPS-derived TEC determined at Hawaii stations after Chile-Illapel EQ, however, these disturbances are found with respect to only one GPS satellite. Lately, Ravanelli et al. (2021) have studied Chile-Illapel event with the use of ground GNSS data. They found the velocities of the gravity waves triggered by the mainshock using the keograms based on the data from selected GNSS PRNs. They have also shown some preliminary scatter representation of these ionospheric disturbances for the first time, but it is suspected that the use of many epochs for displaying by the scatter makes it not very accurate. The current study analyzes more moments related to the Chile event, does not select individual PRNs for the keograms, and shows more evident seismically triggered ionospheric disturbances in the scatters and keograms based on ground GNSS data presents also seismic TIDs along the LEO tracks. Pulinets \& Ouzounov (2018) have analyzed Swarm B along-track ED data related to Chile-Illapel EQ, and they have found the largest disturbance two days before the mainshock. The analyses of Swarm, other LEO data and ground data altogether, can provide interesting observations of ionospheric disturbances not only directly related to the mainshock and tsunami, but also occurring during entire periods of enhanced seismic activity and at larger distances from EQ epicenter.

The objective of this study is to explore more the Chile-Illapel EQ and tsunami on September 16, 2015 and extend the works that can be found e.g., in Reddy et al. (2017) or He \& Heki (2016). The current study analyzes a much longer time period referring to the time before and after the $M_{w}=8.3 \mathrm{EQ}$, which can give more chances for observing potential preseismic and post-seismic signals and provide additional observations useful for the potential detection and warning system (Komjathy et al., 2012). A wider area with respect to mainshock epicenter location is analyzed, including the entire area of South America, southern North America, and Pacific Ocean. A significant extension of this Chile-Illapel 2015 analysis is based on several satellite and ground data types, with a special focus on Swarm and ground GNSS, including GRACE, ionosondes, and seismic records. The tomographic voxel model is also applied in the research, and 4D ED gradients are extracted to reveal the post-seismic TIDs gathered in the model. The satellite data used in the research are Swarm LP in-situ ED, topside TEC from Swarm POD GNSS, and TEC difference based on dualfrequency precise ranging between GRACE satellites. The ground data applied in this study are ground GNSS data from around 200 stations belonging to the Chilean CSN network and Argentina Instituto Geográfico Nacional (IGN) network, as well as two Digisonde stations located in nearby locations with respect to Chile-Illapel event epicenter and evolution, as well as with respect to interesting Swarm passes.

The presented study includes a number of mathematical techniques, including also spectral analyses by short-term Fourier transform (STFT) and continuous wavelet transform (CWT), which are here applied for the first time to Swarm (LP and POD TEC) and GRACE KBR along-track data. Also, combined lately developed techniques (Yang et al., 2019) have been applied in the detection of TIDs. The processing of extended scope of the data with advanced or composed techniques enabled the detection of many interesting pre-seismic and post-seismic ionospheric disturbances of different sizes, at different distances from the event and within different timeframes. Summarizing, this work includes a review of detectable TIDs for an extended timeframe, in a close neighborhood of EQ and more distant places, and proves that wide area, different 


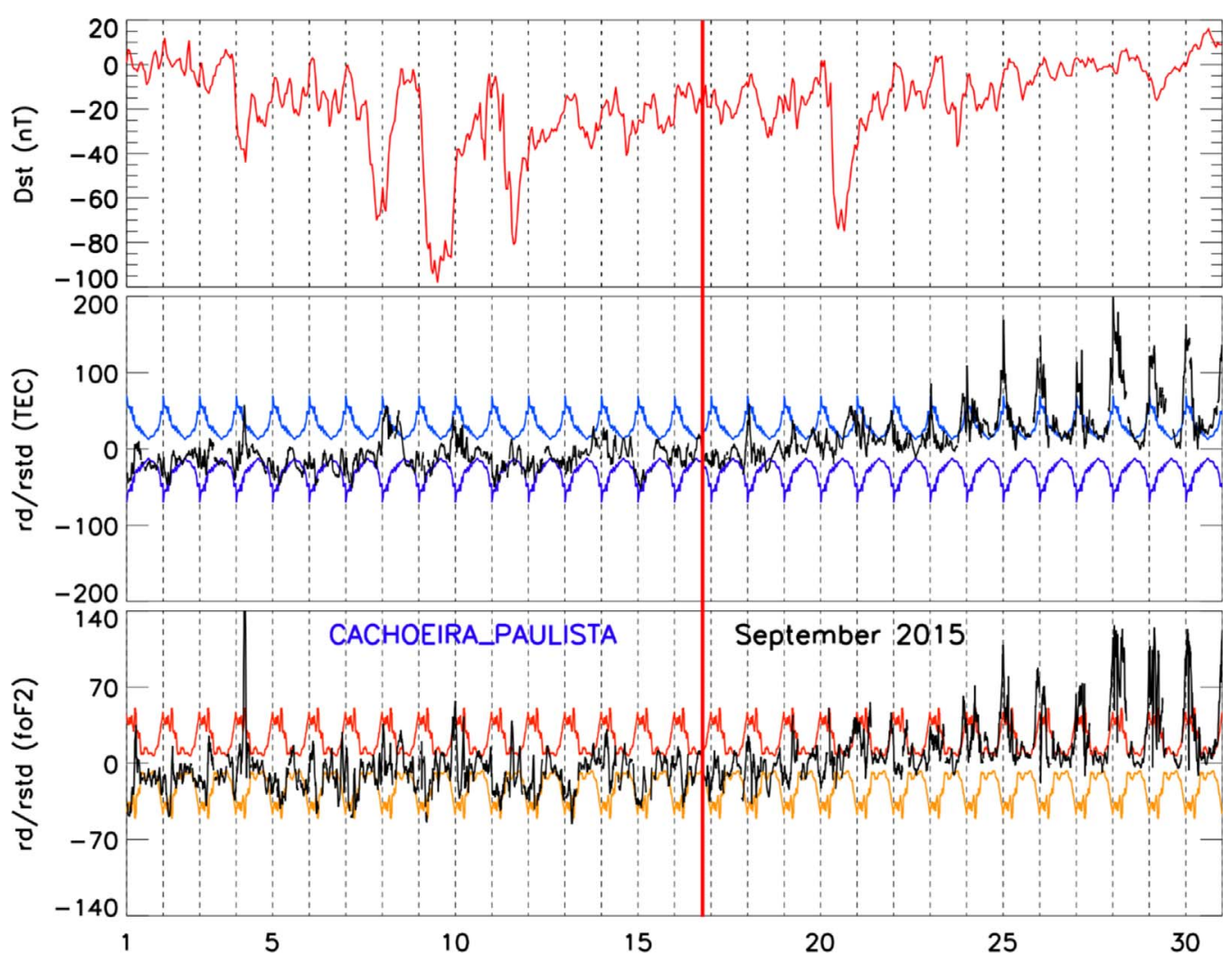

Fig. 4. From top to bottom: the Dst index, and the relative deviation of TEC and foF2 values with respect to monthly medians (black lines) over Cachoeira Paulista (Brazil) during the whole month of September 2015. The color lines represent the relative standard deviation (+/-) of the values taken into account for the estimation of the medians in each case. The latter is included as an indicator of the ionospheric variability in normal conditions that are used as a threshold for identifying significant ionospheric disturbances in a large scale perspective.

altitudes, and extended timeframe are interesting in the analysis of EQ/tsunami event in the context of future prompt detection of the tsunami.

The Chile EQ/tsunami event in 2015 occurred in a period when the magnetosphere was recovered from three consecutive geomagnetic storms on 7, 9, and 12 September 2015, and the values of the Dst-index were still at the level of $-20 \mathrm{nT}$ to $-30 \mathrm{nT}$. Such conditions might trigger perturbation in the ionosphere. To examine the state of the ionosphere, the ionospheric characteristics observed from the Cachoeira Paulista Digisonde station are presented in Figure 4. Cachoeira Paulista Digisonde is in the southern hemisphere, at low latitudes $(-22.70 \mathrm{~S}$, $315.0 \mathrm{E}$ ), at a relatively short distance from the EQ epicenter, and it is expected that large scale ionospheric conditions recorded by this Digisonde station, are representative of the conditions in the wider region of the low latitude zone in the American continent. The data are retrieved by the GIRO (Galkin et al., 2006) and are manually scaled for higher accuracy. Figure 4 presents the relative deviation together with the relative standard deviation of the foF 2 characteristic for reference. This time plot verifies that ionospheric conditions were quiet during the days around the EQ. The relative deviation and the relative standard deviation of TEC from GNSS receivers calculated for Cachoeira Paulista location with the UQRG model (Hernández-Pajares et al., 1999) are also shown in Figure 4. For a few days before and after the EQ, no significant perturbation in TEC and foF2 is observed. A systematic increase in the ionization, seen as a positive deviation in foF2 and TEC, from 24 September until the end of the month is the result of the fast-growing value of the F10.7 index. However, this occurs 9 days after the EQ, and it does not affect the results presented in this paper.

\section{Numerical study by applying data combinations}

\subsection{Close to the epicenter}

\subsubsection{Detection of TEC disturbances from the network of ground GNSS stations}

The composed process for characterizing the TIDs associated with EQ and tsunami is done in two stages (see details in Yang et al., 2019). The first stage consists of the lines of sight computation and GNSS data preprocessing, i.e., obtaining the ionospheric combination from the GNSS carrier phase data, filtering the trend and bias, and mapping the detrended VTEC data, see details in Hernández-Pajares et al. (2006). The technique of detrending employs double-time difference to eliminate the trends in the ionospheric combinations. The selection of the double-time difference delays is justified on the basis of Rolland et al. (2011) and Galvan et al. 2012. Therefore, in this work, we selected double-difference periods of $60 \mathrm{~s}$. and 


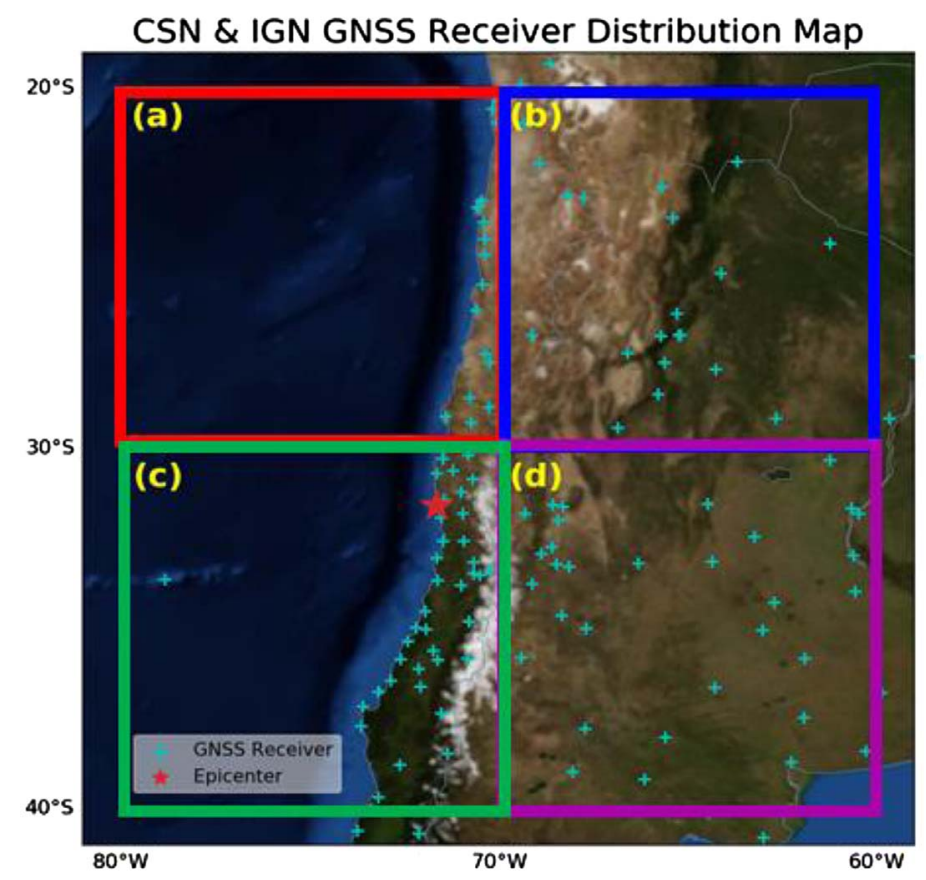

Fig. 5. GNSS receiver distribution in Chile and Argentina. Cyan crosses denote the location of the GNSS receivers, and the red star denotes the epicenter of the $M_{w} 8.3 \mathrm{EQ}$, on September 16, 2015. The grid cells (a)-(d) denote four subnetworks with a geographical grid of $10^{\circ} \times 10^{\circ}$. The ocean depth is shown by the cold color map, originating from the Earth observatory of the US NASA blue marble with topography and bathymetry.

$300 \mathrm{~s}$. The 300-s interval allows for a high sensibility to the tsunami-induced TIDs with the dominant periods in the range of $400-1200 \mathrm{~s}$. The $60-\mathrm{s}$ interval is used to filter the trend and preserve the TIDs with the periods centered around the range of 80-240 s. The TIDs in this range are mostly triggered by the Rayleigh waves and the corresponding acoustic resonance after the EQ. In order to better characterize the gravity waves, we assumed that the most frequent dominant TIDs produced by the interaction between the neutral and ion particles occur below hmF2 (see Hernández-Pajares et al., 2006), and thus we took $200 \mathrm{~km}$ as the mean effective height of the TIDs, which is lower than the average $\mathrm{hmF} 2$.

Chile-Illapel EQ and tsunami induced the ionospheric perturbations recorded by tens of permanent GNSS receivers, i.e., the Chilean CSN network and Argentinian IGN network. By combining these two GNSS networks in the region surrounding the event, we have almost 200 stations at disposal, but the exact number depends on the investigated area. This is much less in comparison to the Tohoku 2011 case, where the density of IPPs obtained from 1200 GEONET stations distributed over Japan is large. Nevertheless, this study aims to prove the detectability of clear and informative observations also from a smaller number and density of stations. In this manuscript, the detailed propagation characteristics of the EQ/tsunami-driven TIDs are studied, and we can show spatial shapes and temporal evolution of ionospheric disturbances. The quantity providing elementary observations of ionospheric disturbances is $L_{\mathrm{G}-\mathrm{F}}=L_{1}-L_{2}$, the geometry-free linear combination of both frequencies carrier phase measurements (also known as ionospheric combination $L_{\mathrm{I}}$, see Hernández-Pajares et al., 2006, 2011; Krypiak-Gregorczyk $\&$ Wielgosz, 2018). Figure 5 presents the region close to the epicenter, divided into four quadrants, according to ADDTID technique assumptions. The division is based on the assumption of different propagation directions and expected characteristics of detected TIDs in different types of area i.e., land and ocean.

The IPP trajectories at $200 \mathrm{~km}$ altitude, recorded from $9 \mathrm{~min}$ before the EQ to $21 \mathrm{~min}$ after the EQ, are shown in Figure 6a. Each color represents the IPPs set from individual GPS satellites. The location of the epicenter is indicated as a red star. The IPPs in green, denoting measurements to the GPS satellite of PRN 12, have recorded the ionospheric variation around the epicenter. For this satellite, the observational data from GNSS receivers whose IPP locations are at a distance of less than $250 \mathrm{~km}$ from the epicenter (marked by the black circle in Figure 6a), are selected in order to describe the relationship between the ionospheric perturbation and EQ and tsunami. The receiver observations were also filtered out under the losses of lock on GPS. Figure $6 b$ depicts the slant TEC from these receivers to PRN 12 by means of $L_{\mathrm{G}-\mathrm{F}}$ in length units, which are arbitrarily aligned in order to clarify the ionospheric variations. Some of arbitrarily aligned STECs around the epicenter show a large "N-shaped" TEC depletion of about 2 TECU appeared about $9 \mathrm{~min}$ after the EQ, in agreement with the 10 min of the arrival time of the acoustic waves associated with the seismic signal up to $221 \mathrm{~km}$ height reported in Artru et al. (2004). These anomalies are similar to a seismic signature and the ionospheric disturbances following the depletion. Yang et al. (2019) also reported similar observations of the sudden decrease of TEC as the response of the ionosphere to the 2011 Japan Tohoku EQ/tsunami.

A typical way to describe TIDs spatiotemporally and estimate their speeds is the keogram of the disturbances, presented in Section 3.1.3, together with the signatures of ionospheric 

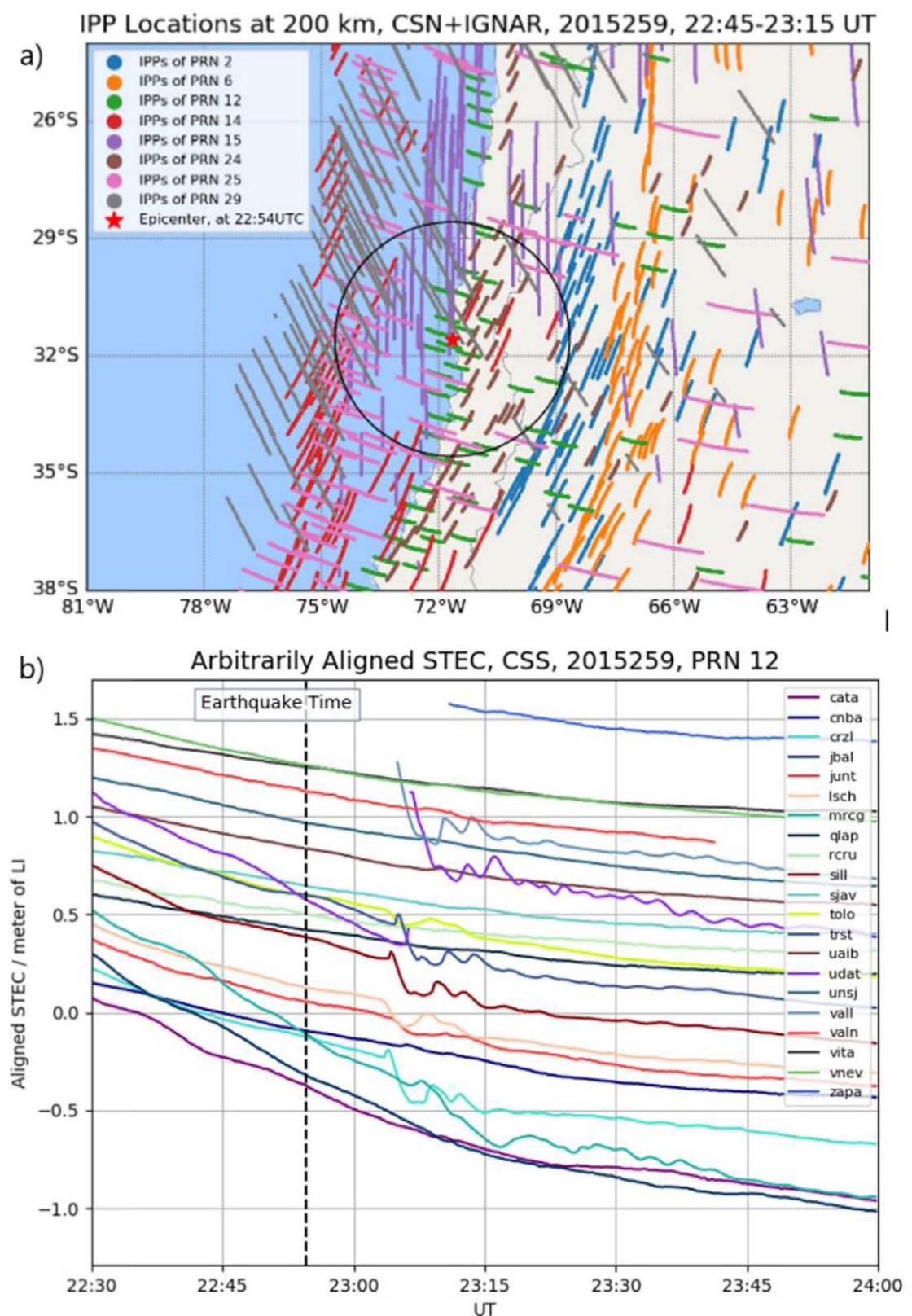

Fig. 6. (a) IPP locations at the height of $200 \mathrm{~km}$, corresponding to the GNSS receivers, from 22:45 to 23:15 UTC, the color codes of cycles for the IPP locations of different GPS satellites, the red star for the location of epicenter, (b) time evolution of the arbitrarily aligned slant TECs, for the GPS satellite of PRN 12, at the time of 22:30-24:00 UTC, the color codes of lines correspond to different GNSS receivers, the black dash line indicates the time of the EQ at 22:54 UTC.

disturbances detected by Swarm LP ED data. The spatiotemporal comparison of disturbances in LEO along-track and ground GNSS data enables to prove sensitivity of LP observations and validate detected ionospheric anomalies onboard Swarm satellites.

\subsubsection{Detection and characterization of TIDs during 2015 Chile EQ/Tsunami by ADDTID}

In the second stage, we detect and characterize the parameters of TIDs by means of the ADDTID algorithm. ADDTID (see details in Yang et al., 2017, 2019) uses data from a dense
GNSS receiver network and can detect and characterize TIDs from the IPPs. The algorithm creates a dictionary of possible waves that encompass the geographical area under study. The estimation is done using only the directly measured detrended VTEC at the expected spectral range and IPP locations and solving a convex optimization problem with a regularization term. This algorithm determines one or few TIDs as the elements of the dictionary that best approximate the observations. Despite a small number of stations, the TIDs during the 2015 Chile EQ/Tsunami can be studied by the ADDTID method (see also its application to dense GNSS network in Yang et al., 2017, 2019). In order to analyze the local behavior 


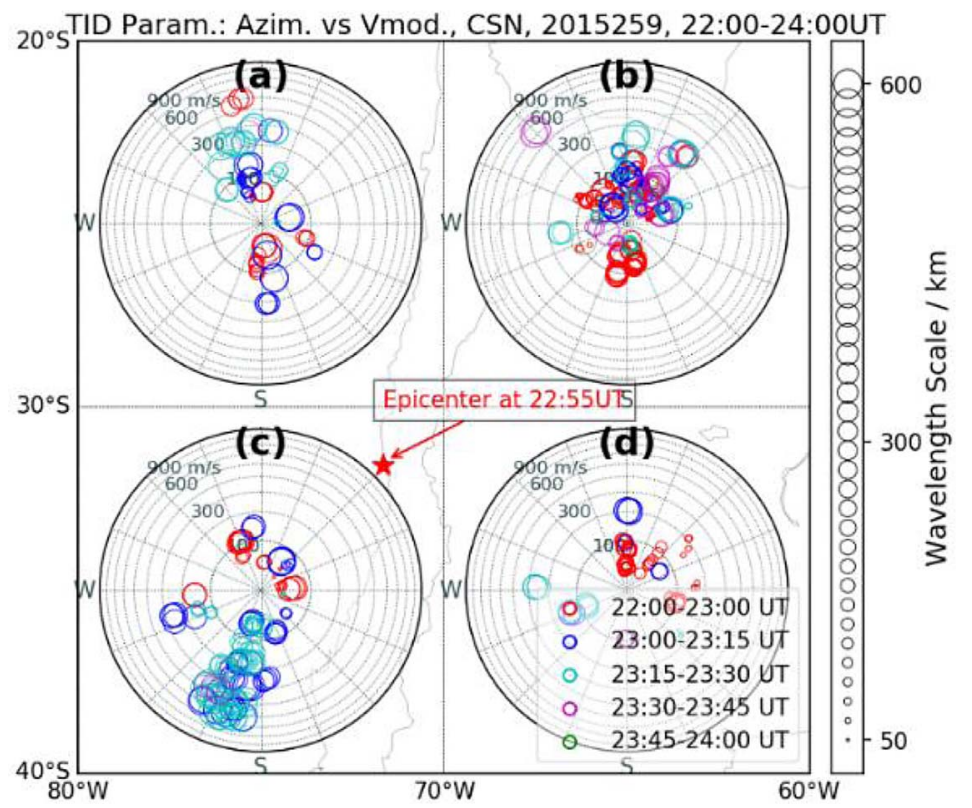

Fig. 7. Detected MSTIDs of each subnetwork. Parameter evolution of detected TIDs before the EQ during 22:00-24:00 UTC, representing non-uniformly scaled polar plots for TIDs of the corresponding grid networks (a)-(d), the location representing for the azimuth vs. velocity of 0-360 degree and 0-900 m/s, the circle size for wavelength of 50-600 km, and the color code for different time intervals.

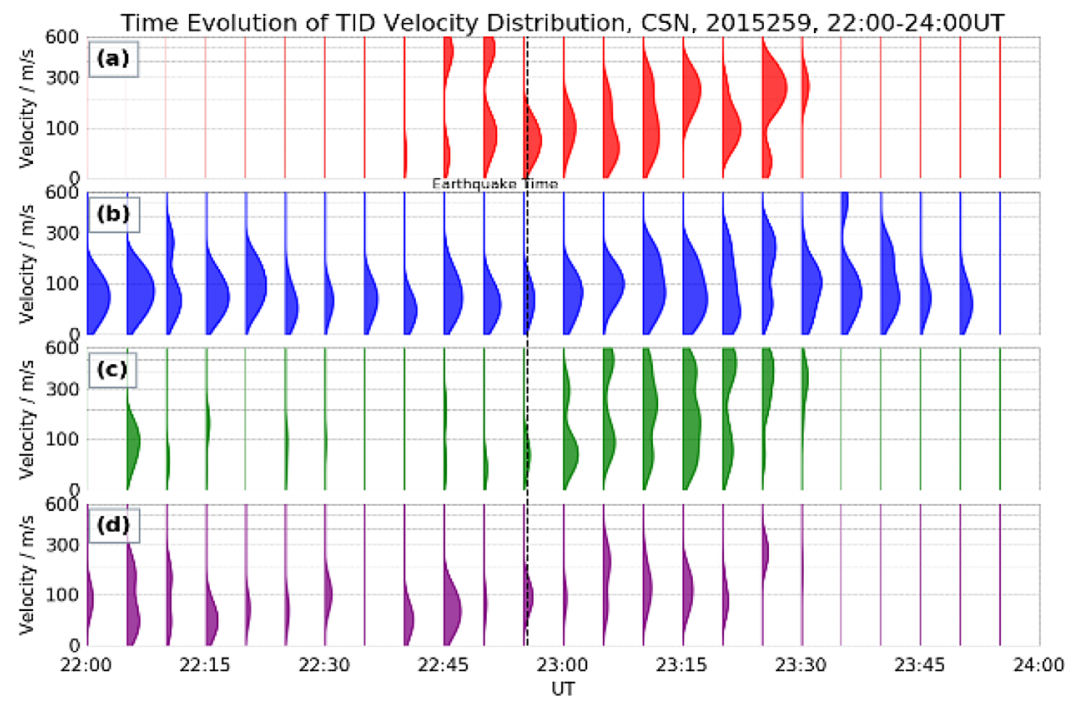

Fig. 8. Time evolution of TID velocity distribution during 22:00-24:00 UTC, for the subnetwork (a), (b), (c), and (d), respectively. The scale of the velocity axis ranges from $0 \mathrm{~m} / \mathrm{s}$ to $600 \mathrm{~m} / \mathrm{s}$.

of TIDs, the network has been divided into 4 geographical grids of $10^{\circ} \times 10^{\circ}$ (Fig. 5). The propagation parameters of the local TIDs from one hour before the EQ to one hour after the EQ, are described in the polar plots in Figure 7. Figure 8 describes the time evolution of the estimated TID velocity distribution from 22:00 to 24:00 UTC for the subnetworks (a), (b), (c), and (d), respectively. These plots show MSTIDs moving at the highest velocities (above $300 \mathrm{~m} / \mathrm{s}$ ) towards the deep sea and further away from the epicenter, fully in agreement with the expected tsunami-related ionospheric signatures. It should be noted that the intensity of the TIDs is taken as the weights for the heights of histograms, which then can be easily read. The results estimated by ADDTID clearly show a set of strong TIDs appearing a few min after the EQ and later (see dark blue and light blue points, in Fig. 7). Also, the occurrences of the strong local TIDs in the grids of the network (subplots (a) and (c) pointing mainly to the sea) can give a clue to indicate the current location of the tsunami. 


\subsubsection{Comparison of detected pre-seismic and co-seismic ionosphere disturbances by Swarm LP ED, Swarm POD TEC, and ground GNSS data}

This section analyzes the ionosphere disturbances detected mainly by Swarm LP ED and POD TEC in three time periods, selecting the time when interesting Swarm passes over the Chile-Illapel vicinity are available. The EQ of magnitude 8.3 took place on September 16, 2015 at 22:54, however, the orbits of Swarm B just after this EQ were more than $2000 \mathrm{~km}$ to the west of this event, and Swarm A/C orbits were distant even more than $3000 \mathrm{~km}$. This is too far for the observation of starting $\mathrm{EQ} /$ tsunami event. Swarm satellites $\mathrm{A} / \mathrm{C}$ passed this region on September 16, 2015 around 20:00 UTC, whereas Swarm B passed the region around 22:00 UTC. This latter track of Swarm $\mathrm{B}$ is investigated later in Section 3.1.3 in detecting close preseismic TIDs. The closest available Swarm track after the mainshock in terms of close time and location is recorded on September 17, 2015, 7:25 AM (Fig. 19), and this time also corresponds to tsunami propagation time. This pass of Swarm A took place around $8.5 \mathrm{~h}$ after $M_{w}=8.3 \mathrm{EQ}$ when there were many aftershocks, and the tsunami was in the middle phase of the propagation in the ocean.

LEO along-track data are compound 1D signals that can be analyzed by 1D STFT, an evolutionary form of discrete Fourier transform (DFT) (Harris, 1978). In this study, Swarm LP ED and POD TEC signals are high-pass filtered by DFT. The classification of the spectral characteristics of disturbing along-track signals by STFT is supported by their simultaneous search in ground GNSS observations, which gives an opportunity for the validation of spectral recognition. STFT spectral approach to along-track Swarm data gives an opportunity for distinguishing the signals of different origins. Firstly, we analyze Swarm B pass in UTC evening on September 10, 2015, which is six days before the mainshock. Secondly, we study Swarm B at the moment, just before the Chile-Illapel mainshock and analyze ground GNSS data also up to an hour after this EQ on September 16, 2015. Thirdly, we inspect the closest possible Swarm A/C pass after the mainshock in the morning of September 17, 2015. At these three moments, Swarm detection of a possible TID and its validation by ground GNSS data is made in the following three steps. Firstly, STFT spectrograms are made for the selected LP ED high-pass filtered observations, using $70 \mathrm{~s}$. Tukey window. The ED measured by LP and POD TEC is high-pass filtered by DFT decomposition, and the signals that have a period larger than $70 \mathrm{~s}$ along the track at its altitude are removed. This time interval corresponds to around $500 \mathrm{~km}$ or $4.5^{\circ}$ along the Swarm orbit, which is assumed as the upper limit for disturbances interesting from the seismic point of view (see e.g., Rolland et al., 2011; Chou et al., 2020). Additionally, we can see in Pulinets \& Ouzounov (2018, p. 4-25) that this period seems reasonable and large enough with respect to the seismic disturbance observed by them on September 14, 2015, and small enough with respect to Equatorial Ionospheric Anomaly (EIA) crests and Suninduced features of ED along-track record. It can be noticed at first look that detected potential anomalies on September 14, 2015 are of higher frequency than different characteristic components of EIA. It should be stressed that Fourier-based filtering avoids the remaining long-wavelength features of the signal with respect to gradient-based methods, which are approximate filters. The PSD from the spectrogram is sampled at a frequency of $50 \mathrm{~s}$ in order to visualize large PSD values along the Swarm track together with a scatter plot of ground GNSS data. Secondly, the keogram based on band-pass filtered $\mathrm{L}_{\mathrm{G}-\mathrm{F}}$ combination of phase data (Hernández-Pajares et al., 2006, 2011; Krypiak-Gregorczyk \& Wielgosz, 2018), and distances calculated from the epicenter is prepared and overlayed with the selected Swarm LP ED spectrogram section in order to identify the potential spatiotemporal correlation of TID in these two data sets. The $L_{\mathrm{G}-\mathrm{F}}$ is band-pass filtered by DFT between the period from $1800 \mathrm{~s}$ to $240 \mathrm{~s}$, which is a slightly wider range than in Section 3.1.1. However, a larger interval is intentional for the overview keograms of larger areas and timeframes, where we expect a wider spectrum of disturbances to recognize. The primary assessment of character and origin of disturbances can be found in Section 3.1.2 and continued here with the help of keograms and scatters. In the third step, the scatter plots describe several min. of $L_{\mathrm{G}-\mathrm{F}}$ from ground GNSS data and respective several min. of ED spectrogram section along the Swarm orbit are directly spatiotemporally compared. The disturbances observed by Swarm and reflected in large PSD along the orbital track can be directly visually compared to TIDs present in ground GNSS observations. TIDs in-ground GNSS data are visible as colored strips (e.g., Fig. 9) with positive slope, which travels outward from the seismic sources, with all velocities around $0.3 \mathrm{~km} / \mathrm{s}$., which makes them most similar to gravity waves (Galvan et al., 2012; Jin et al., 2014; Occhipinti et al., 2013). The disturbances in Swarm ED can be found at the selected frequencies of spectral patterns. It should be stressed that IPPs, which indicate the location of $L_{\mathrm{G}-\mathrm{F}}$ phase combination data are referred in this case to the altitude of $450 \mathrm{~km}$, which gives coincidence with in-situ LP data from Swarm A, and approximate coincidence with slightly higher orbit of Swarm B.

The sample day September 10, 2015, where evidence of medium-scale ionospheric irregularities was found, precedes the mainshock by six days. As investigated in Section 1.1, different authors select different periods before the main EQs to observe potential pre-seismic ionospheric anomalies (see e.g., De Santis et al., 2019; Liu et al., 2006b), and the discussion in this field is open. It is also possible that these observations still correspond to the local winter, which shows typical MSTIDs climatology during daytime and equatorward propagation (see for instance, Hernández-Pajares et al., 2012). The selection of September 10, 2015 is based on the preliminary observation of simultaneous Swarm LP and ground GNSS anomalies in the keogram in Figure 9, which presents bluered strips at different distances from the mainshock location. Some ionospheric disturbances in Figure 9 coincide with a larger Swarm PSD at period 35-40 s, indicating in-situ ED disturbance. The spatial directions of the GNSS satellite-station phase measurements are often do not coinciding with TIDs. Therefore, the larger number of ground GNSS TEC determination points (IPPs), the better are TIDs observations. There are two passes of two Swarm satellites accessible in the time epoch shown in Figure 9. The disturbances in-ground GNSS data at the time of Swarm A pass slightly disappear for some time and come back after this pass. However, Swarm B crosses exactly the TIDs just after 22:00, when the preceding storm 


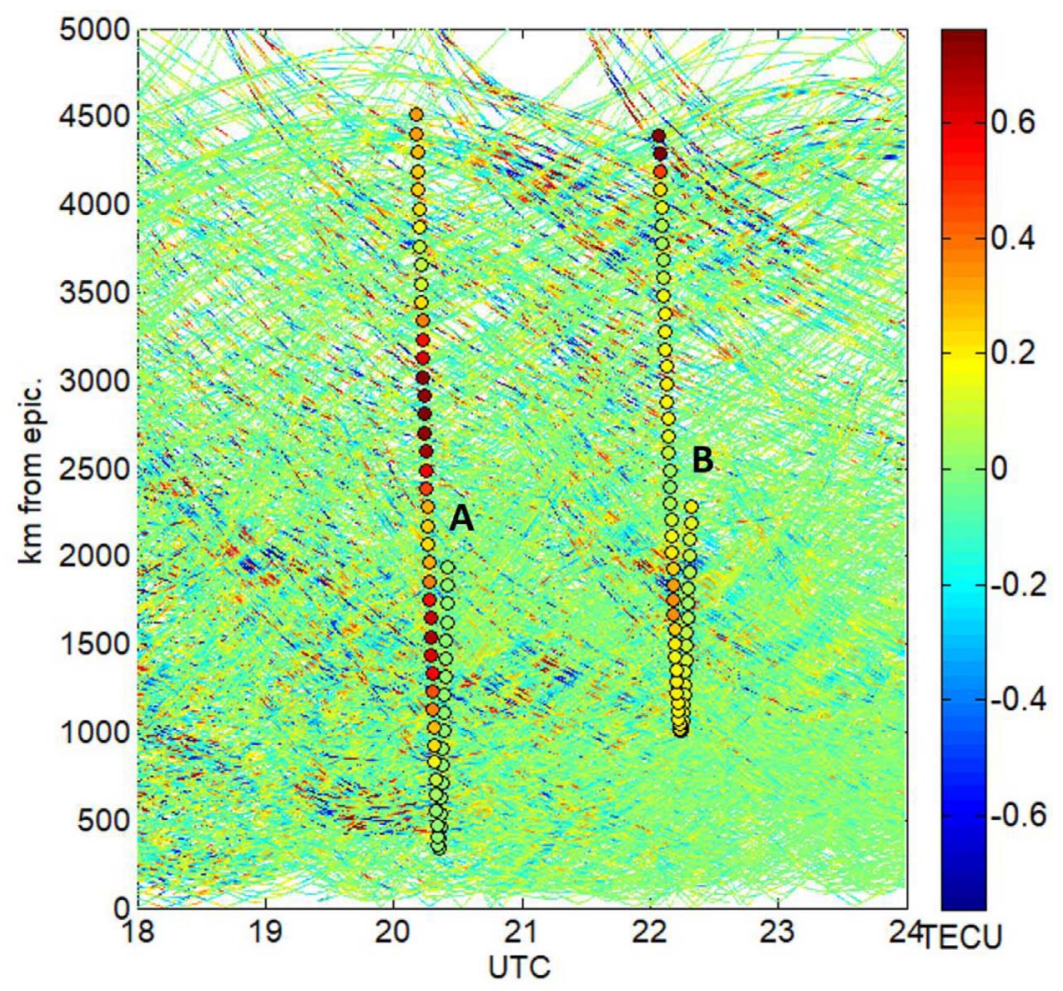

Fig. 9. Keogram of bandpass filtered $L_{\mathrm{G}-\mathrm{F}}$ phase combination from ground GNSS stations of Chilean and Argentinian networks, recalculated to TEC units, in the UTC evening on September 10, 2015. All distances of IPP tracks are calculated with respect to the position of the mainshock. Large dots denote Swarm A and B passes with distances respective to the mainshock location, and their color indicate size of power PSD sampled at $50 \mathrm{~s}$. from the spectrogram. The blue-red strips denote different TIDs.

from 9.09 calms down, and the Dst index is around $-20 \mathrm{nT}$ (Fig. 4, top). The relative TEC changes are also small at this time (Fig. 4, middle). After signal high-pass filtering to $70 \mathrm{~s}$, we can find a disturbance in Swarm LP ED, which can be analyzed by the spectrogram (Fig. 10c). This disturbance has a frequency starting from around $40 \mathrm{~s}$, which then simultaneously decreases and increases, so its frequency splits into different frequencies. We can see in Figure 10b that TEC anomaly over the Altiplano minor plate is separated from EIA and that ED anomalies detected by Swarm are not necessarily co-located with the highest TEC anomalies.

A preliminary coincidence of Swarm B disturbance and TIDs in-ground GNSS data (Fig. 9) must be inspected by the scatter plot because the keogram indicates only a common distance of the observations from the epicenter and not necessarily a common location. The PSD from the spectrogram sampled at $50 \mathrm{~s}$ frequency is visualized along several min. of the Swarm B track, together with the same amount of ground GNSS $L_{\mathrm{G}-\mathrm{F}}$ data in Figure 11. We can see clear TIDs located easterly from the Altiplano plate edge and exactly co-located with Swarm pass and the disturbance of changing frequency presented in the spectrogram in Figure 10c. The location of these TIDs parallel to the Altiplano edge and their speed similar to gravity waves makes their seismic origin fairly probable.

The closest Swarm track preceding the mainshock is the Swarm B track occurring on September 16, 2015 around 21:50 UTC, which is $1 \mathrm{~h}$ before the mainshock. The TIDs preceding the mainshock have again the speeds similar to gravity waves (Galvan et al., 2012; Jin et al., 2014; Occhipinti et al., 2013). Some of the TIDs, which are noticeable in the keogram before the mainshock (Fig. 12), coincide in time and distance from the epicenter with Swarm B passing across this region. The spectrogram of Swarm B in-situ measured ED (Fig. 13c) and accompanying UQRG TEC map (Fig. 13b) show ionospheric disturbance and TEC enhancement above the Altiplano minor plate, respectively. The period of the anomaly centered rather at $50 \mathrm{~s}$, decreases at the end but also has some higher frequencies of lower power accompanying the most evident one. The scatter plot of $L_{\mathrm{G}-\mathrm{F}}$ in Figure 14 presents some correlated disturbances slightly westerly and easterly from the Swarm B track. However, it should be pointed that the density of IPPs is not satisfactory in the area of Altiplano plate and these disturbances probably could also cross the Swarm footprint in case of more dense data. It is probable that two places of noticeable TIDs in Figure 14 surrounded by black rectangles are continuous concentric rings of perturbations, and their ionospheric response is here broken due to the small number and adverse directions of STEC measurements. Quite good and long continuity of these disturbances can, however, be found in the keogram in Figure 12.

One hour later, when no Swarms are available, the $M_{w}=8.3$ EQ has generated TIDs easily detectable in the band-pass filtered ground GNSS data. TIDs are mostly composed of circular waves centered at the EQ epicenter, and with velocity 

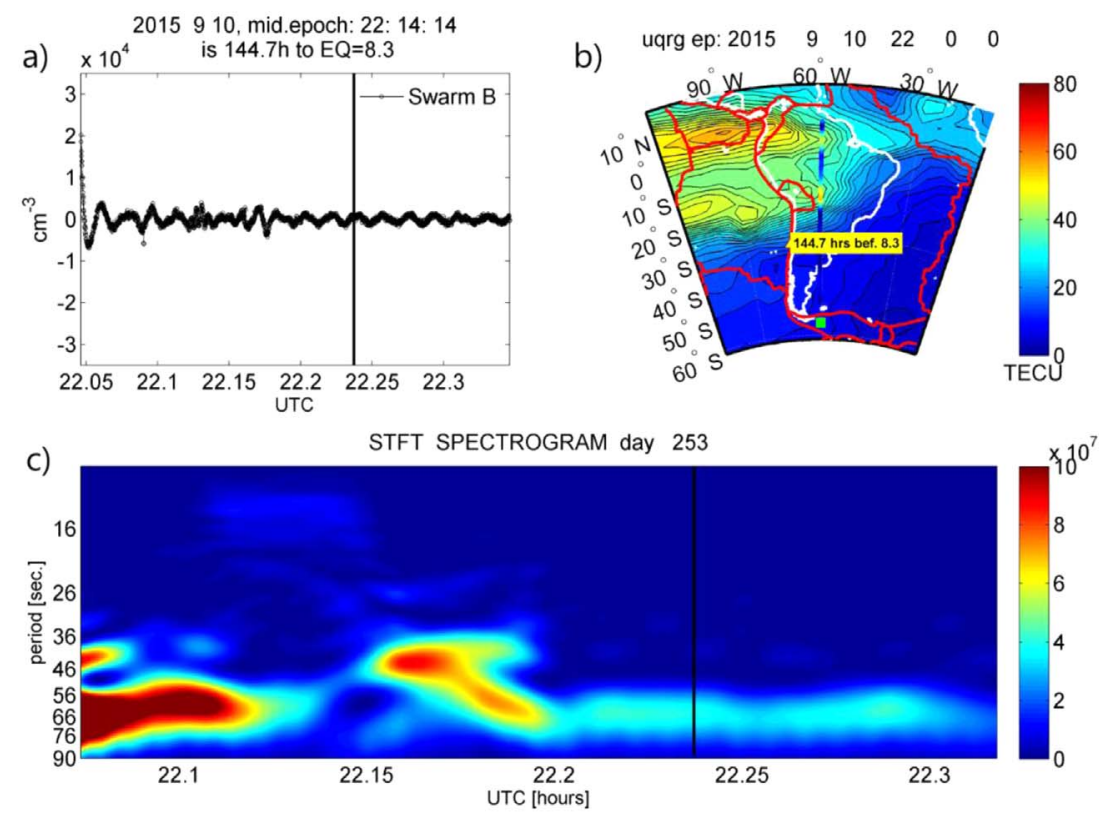

Fig. 10. (a) Swarm B LP high-pass filtered ED data, (b) STFT spectrogram of residual ED, and (c) the closest UQRG GIM epoch with overlayed Swarm B along-track PSD section of ED at frequency 50 s. South America region on September 10, 2015. Black line (top-left and bottom) denotes the time of passing the latitude of mainshock.

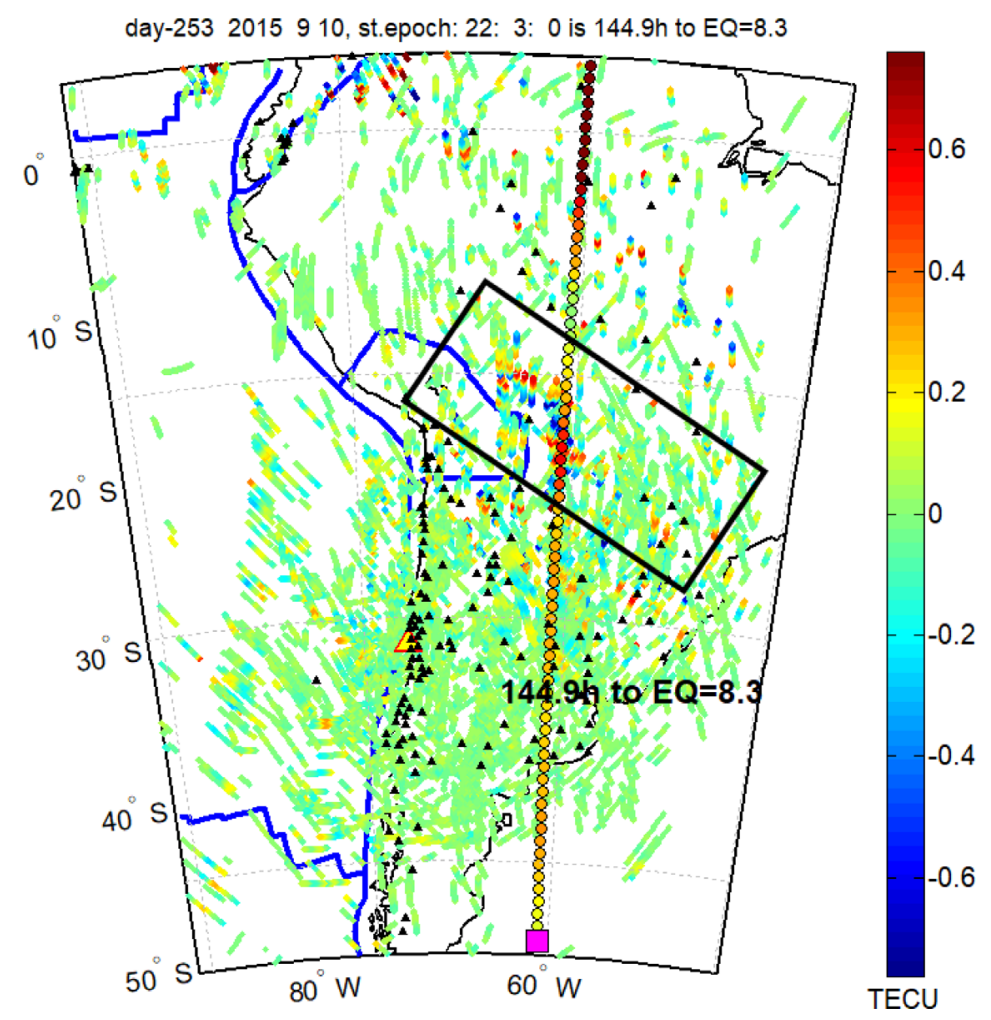

Fig. 11. Scatter map of around 16 min of band-pass filtered phase $L_{\mathrm{G}-\mathrm{F}}$ combination from ground GNSS stations of Chilean and Argentinian networks (black triangles), recalculated to TEC units, on September 10, 2015. Larger dots indicate Swarm B along-track power spectrum of LP ED disturbances sampled from the spectrogram at $50 \mathrm{~s}$. Magenta square is the last Swarm position indicating the direction of flight. Blue lines are tectonic plate boundaries. Black rectangles indicate places of the most evident TID. Yellow triangle is the epicenter of Chile-Illapel EQ. 


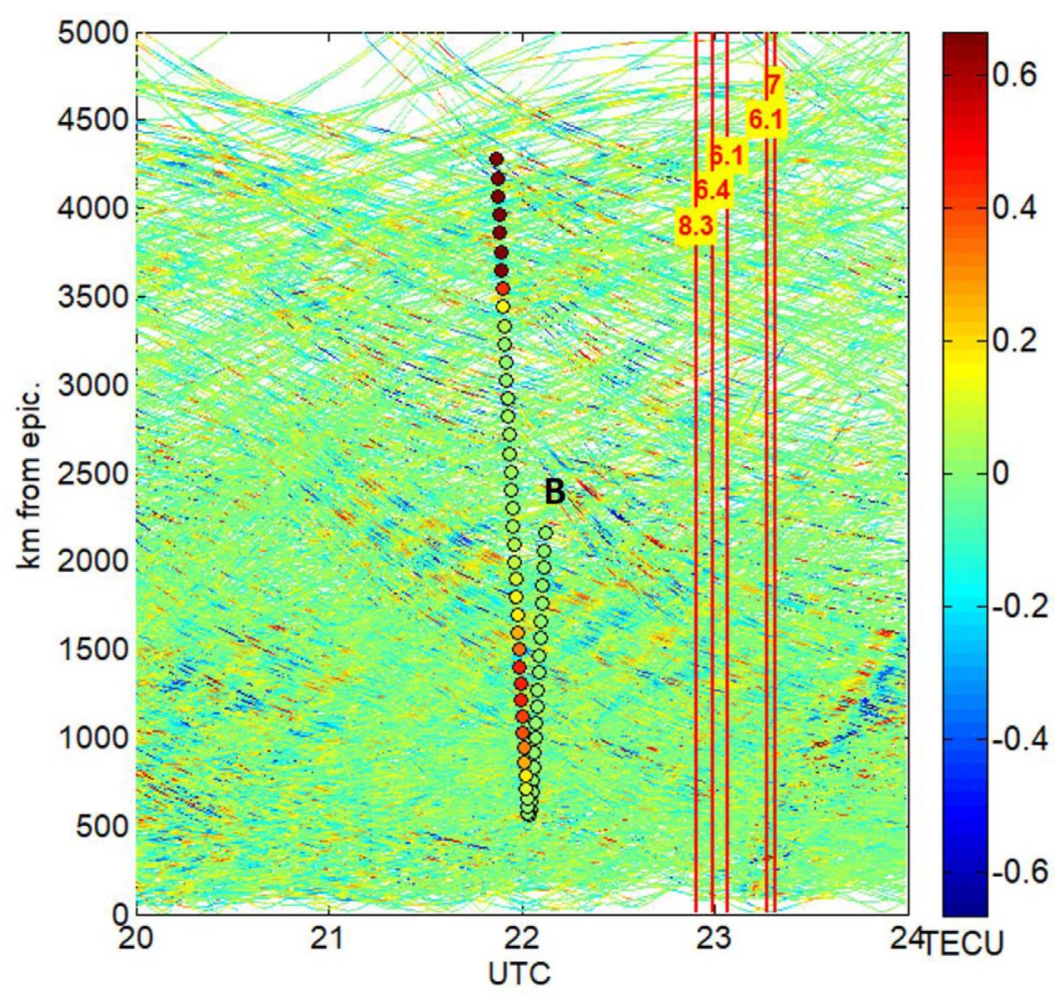

Fig. 12. The same as in Figure 9, in the UTC evening on September 16, 2015. The vertical lines with label denote Chile-Illapel $M_{\mathrm{w}}=8.3$ mainshock and aftershocks. The blue-red strips in the right-bottom corner are TID directly related to the mainshock. The other blue-red strips denote other pre-seismic ionosphere disturbances.
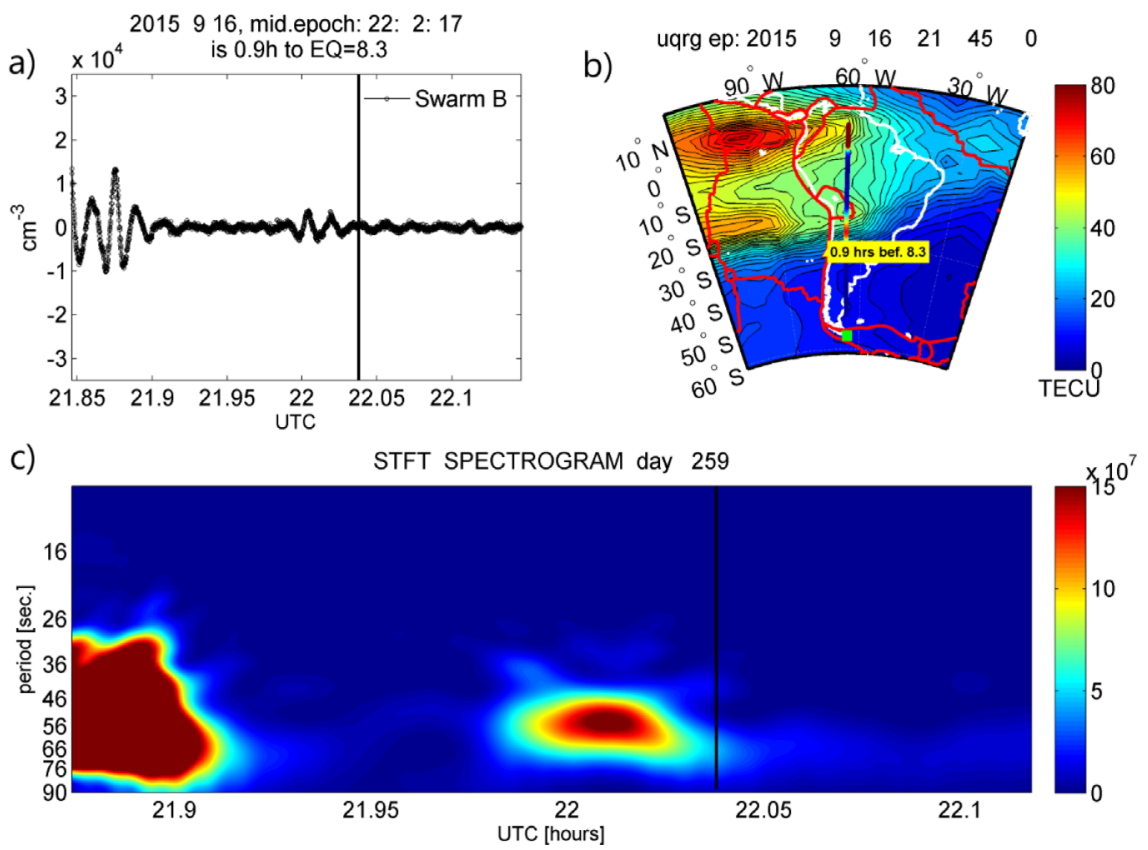

Fig. 13. The same as in Figure 10. Swarm B, South America region on September 16, 2015, less than $1 \mathrm{~h}$ before the mainshock.

around $0.5 \mathrm{~km} / \mathrm{s}$ are most probably due to acoustic waves induced by the Rayleigh waves, by dynamic coupling, and propagating upward in the atmosphere strongly amplified by the combined effects of the decrease of atmospheric density and the conservation of kinetic energy density (Occhipinti et al., 2018). The TIDs triggered by the mainshock are easily 


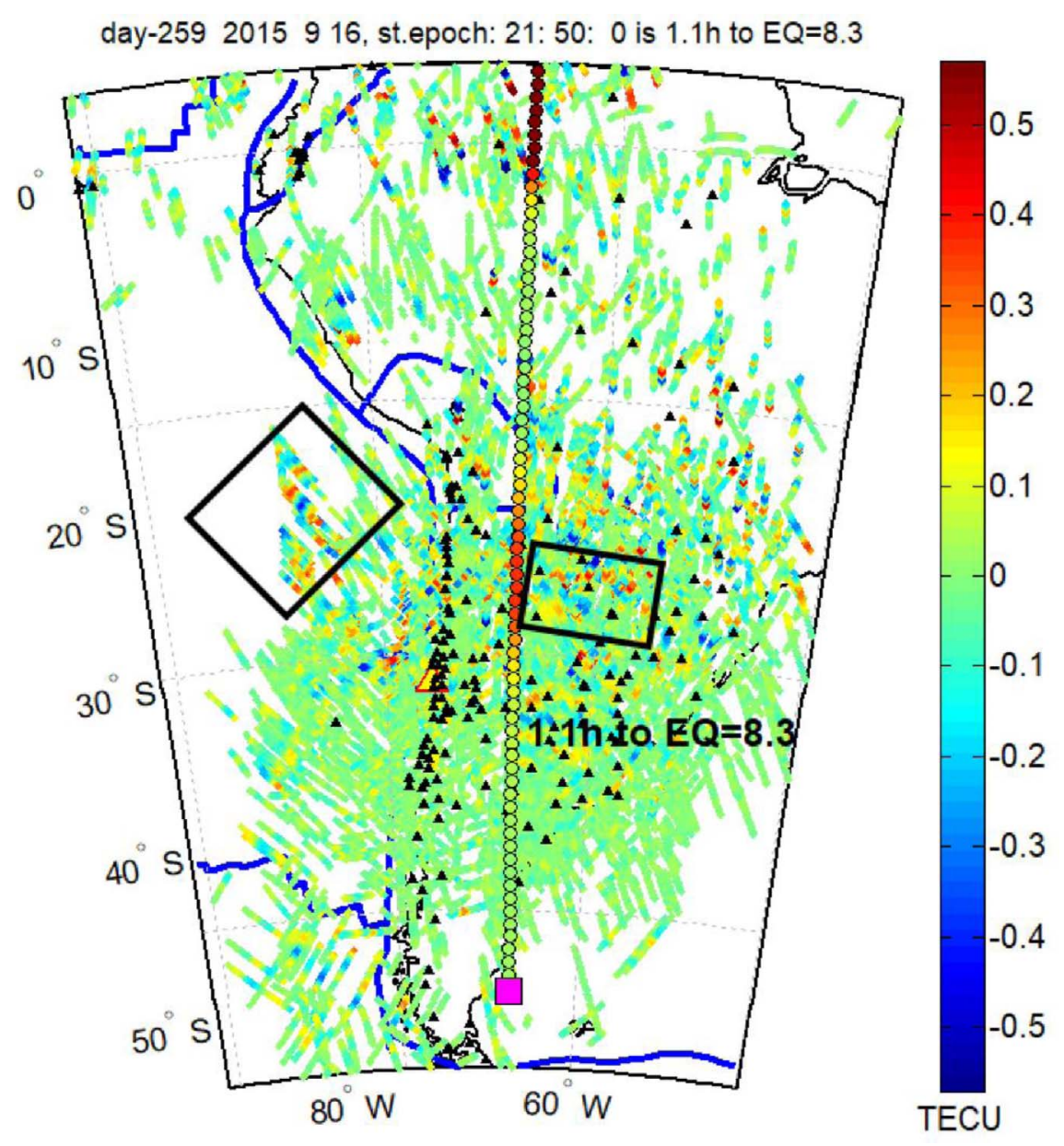

Fig. 14. The same as in Figure 11, on September 16, 2015, $1.1 \mathrm{~h}$ before the mainshock.

noticeable in the right-bottom corner of Figure 12. These disturbances, which have higher speeds than TIDs before the mainshock, can also be presented in the scatter plot as concentric traveling rings (Fig. 15). Several close aftershocks occurred just after the mainshock, indicated by red vertical lines in Figure 12.

The closest possible Swarm passes after the Chile-Illapel EQ of $M_{w}=8.3$ are available in the morning of September 17, 2015, $8 \mathrm{~h}$ after the mainshock. The first pass of Swarm A over this region was at 7:22 AM UTC, which is 3:22 AM of Chilean time. The Sun was on the opposite side, and the TEC values were small at that time (Fig. 17b). Much lower Sun activity directly reflects in much weaker red-blue strips in the keogram (Fig. 16). TIDs can be found for the last time in Figure 16 around 7:00-8:00 AM UTC and are almost undetectable in the next hours. In Figure 16 we see again that not all station-PRN sounding directions can cross TIDs, and redblue strips are often separated by undisturbed, green IPPs. Therefore, many authors select GNSS satellites in the keogram creation to have an effect of continuous TIDs, which is avoided in this work to better show the ionosphere behavior. The ED spectrogram and scatter plot are prepared only for the time of the first pass of Swarm A around 7:22 UTC (Fig. 16, leftmost track), which as the only one reaches some blue-red strips moderately visible in the keogram. The spectrogram of this pass (Fig. 17c) shows clear disturbances over the Altiplano plate and over the continent (Fig. 17b), which are of a smaller amplitude in relation to that observed during afternoon hours in the previous figures (e.g. Fig. 10).

POD TEC signals are expected to provide similar disturbances in relation to LP ED data, with some exceptions. The STEC measurements between Swarm A spacecraft and GNSS satellites point in spatially different directions. Therefore, in-situ LP detection of ionosphere perturbation can be absolutely not reflected in POD STEC measurement in case when its direction does not coincide with disturbing wave direction. However, there is always some chance, and it is worth analyzing Level 2 POD TEC product. STEC is recalculated to VTEC at IPP altitude $50 \mathrm{~km}$ above the Swarm A. In STFT analysis, we use VTEC with exactly the same parameters as for LP data analysis. The difference is only in the power spectrum maximum range in the plots, which is different due to different data types. The position of GPS IPPs with respect to Swarm A orbit can be found in Figure 18b, as respective locations of colored PSD sections and magenta lines. The POD TEC measurement from Swarm A corresponding best to LP ED 
day-259 20159 16, st.epoch: 23: $37: 0$ is $0.7 \mathrm{~h}$ after $E Q=8.3$

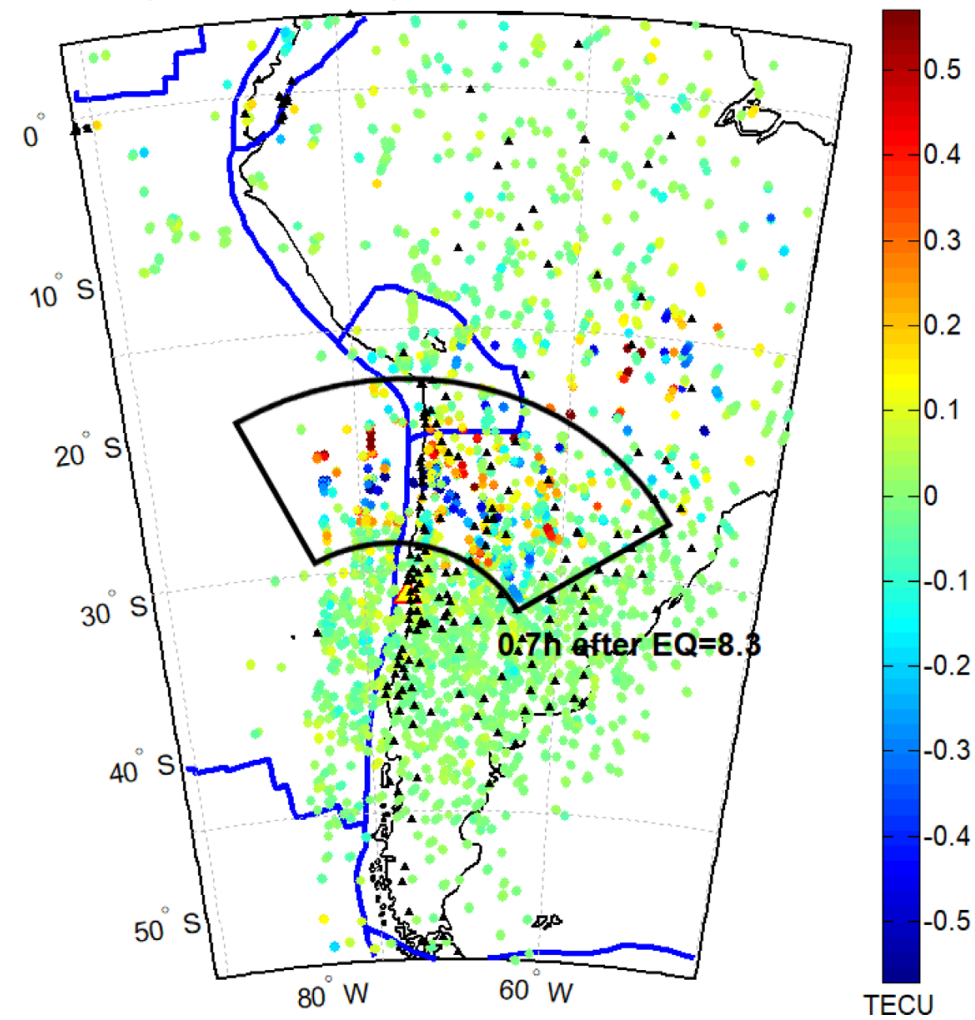

Fig. 15. Scatter map of two close epochs of band-pass filtered phase $\mathrm{L}_{\mathrm{G}-\mathrm{F}}$ combination from ground GNSS stations of Chilean and Argentinian networks, recalculated to TEC units, on September 16, 2015, $0.7 \mathrm{~h}$ after the mainshock. Blue lines are tectonic plate boundaries. Black outline marks places of the most evident TID.

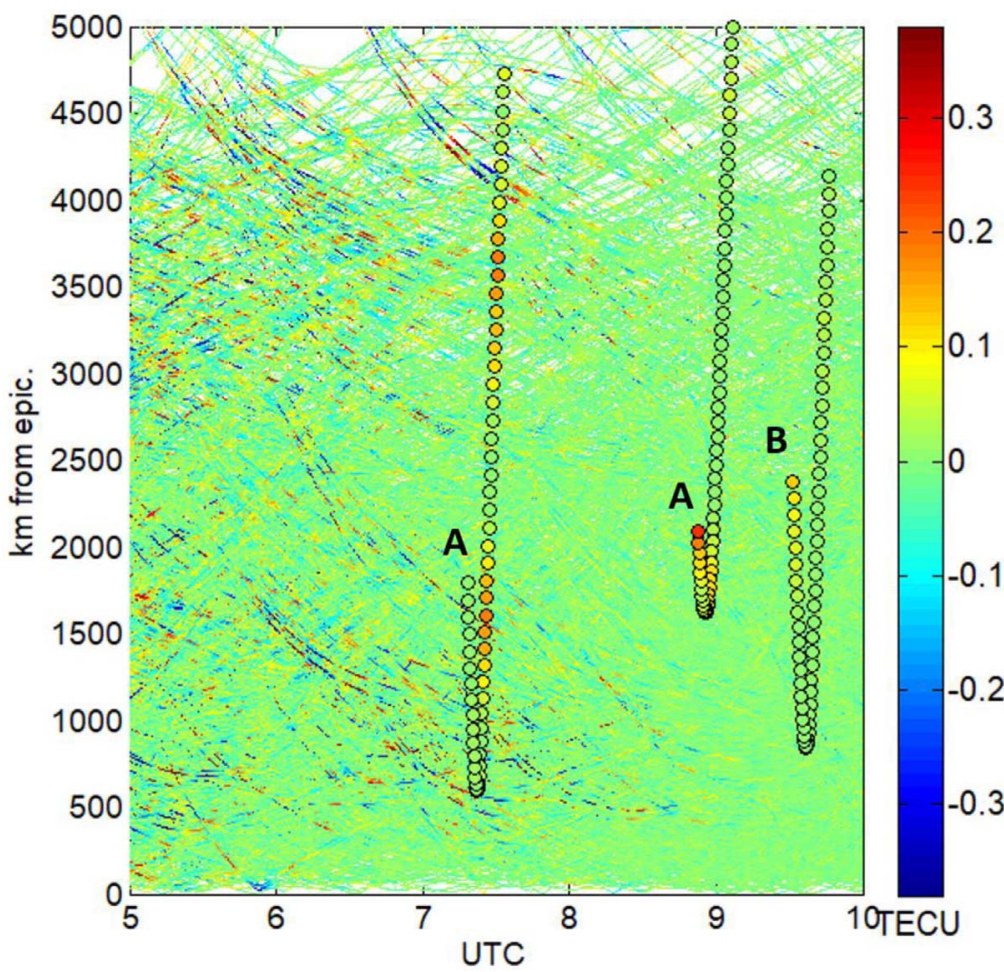

Fig. 16. The same as in Figure 9, in the UTC morning on September 17, 2015. The blue-red strips denote different TIDs, which are less detectable in the morning. 

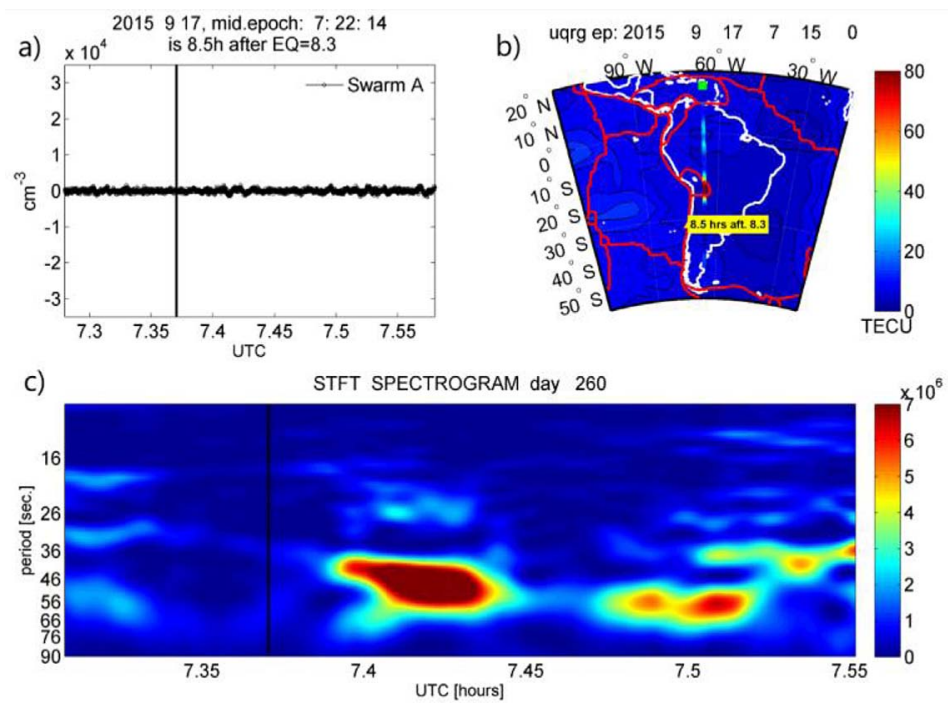

Fig. 17. The same as in Figure 10. Swarm A, South America region on September 17, 2015.

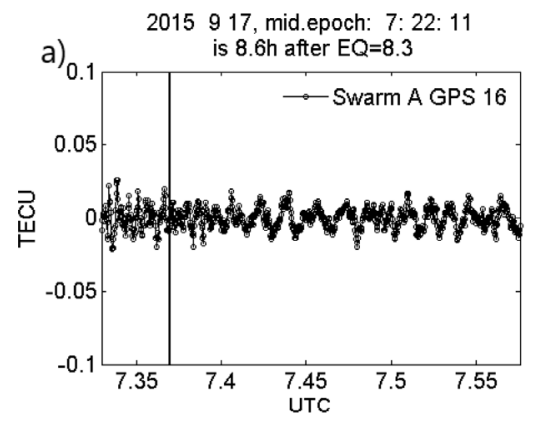

b)
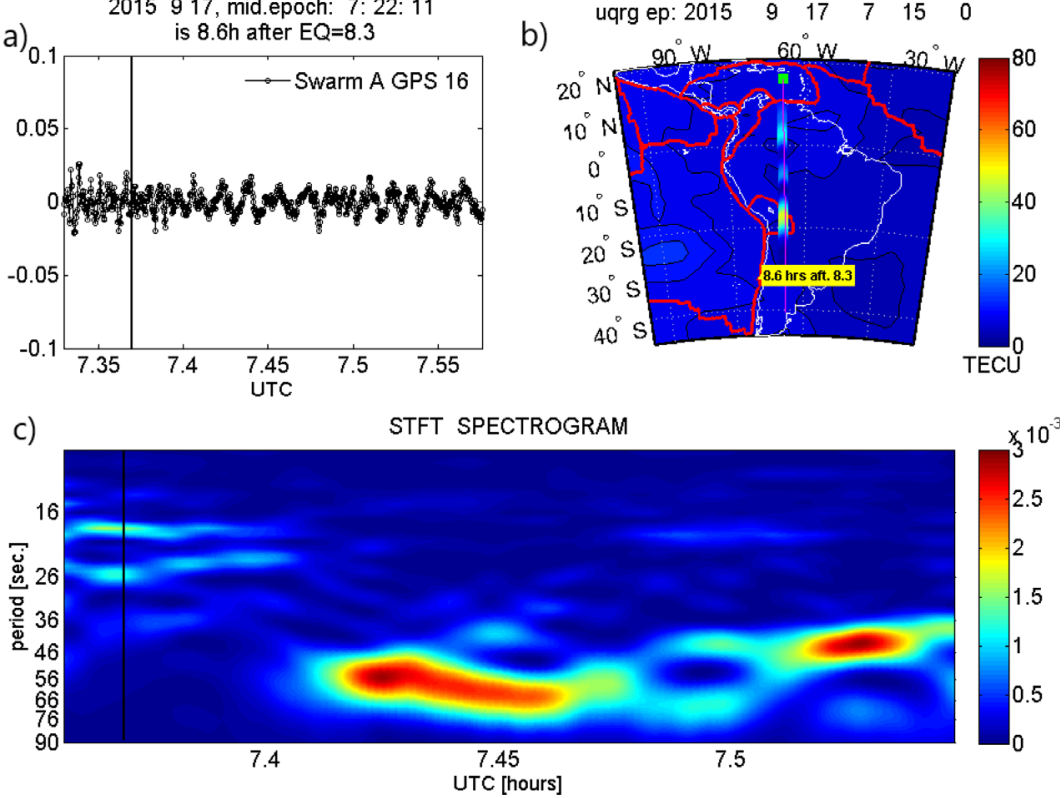

Fig. 18. The same track as in Figure 17, (a) Swarm A - GPS 16 POD TEC high-pass filtered data, (b) the closest UQRG GIM epoch with overlayed Swarm A along-track PSD section of TEC at frequency $50 \mathrm{~s}$, and (c) STFT spectrogram of residual POD TEC. Black line (a) and (c) denotes the time of passing the latitude of mainshock.

signal is taken to PRN 16, which flies west of Swarm A (Fig. 18b).

The scatter plot of $L_{\mathrm{G}-\mathrm{F}}$ in the morning of September 17 , 2015 finds TIDs directed to the ocean, which does not coincide exactly with the disturbances along with the Swarm A track (Fig. 19). These presumable TIDs are located quite close to and westerly from the epicenter of Chile-Illapel, over the ocean, which seems not to be related with the expected seasonal
MSTIDs in the winter-spring transition due to its occurrence in the local night (Hernández-Pajares et al., 2012), but it does not exclude their relation with the tsunami. However, the gaps in IPP data significantly impede the exact recognition of their shapes. These disturbances, however, are away from the strong Sun activity, which additionally proves their seismic origin. The disturbance along the track of Swarm A in Figure 17, which can be recognized clearly with the use of STFT, can suggest that 


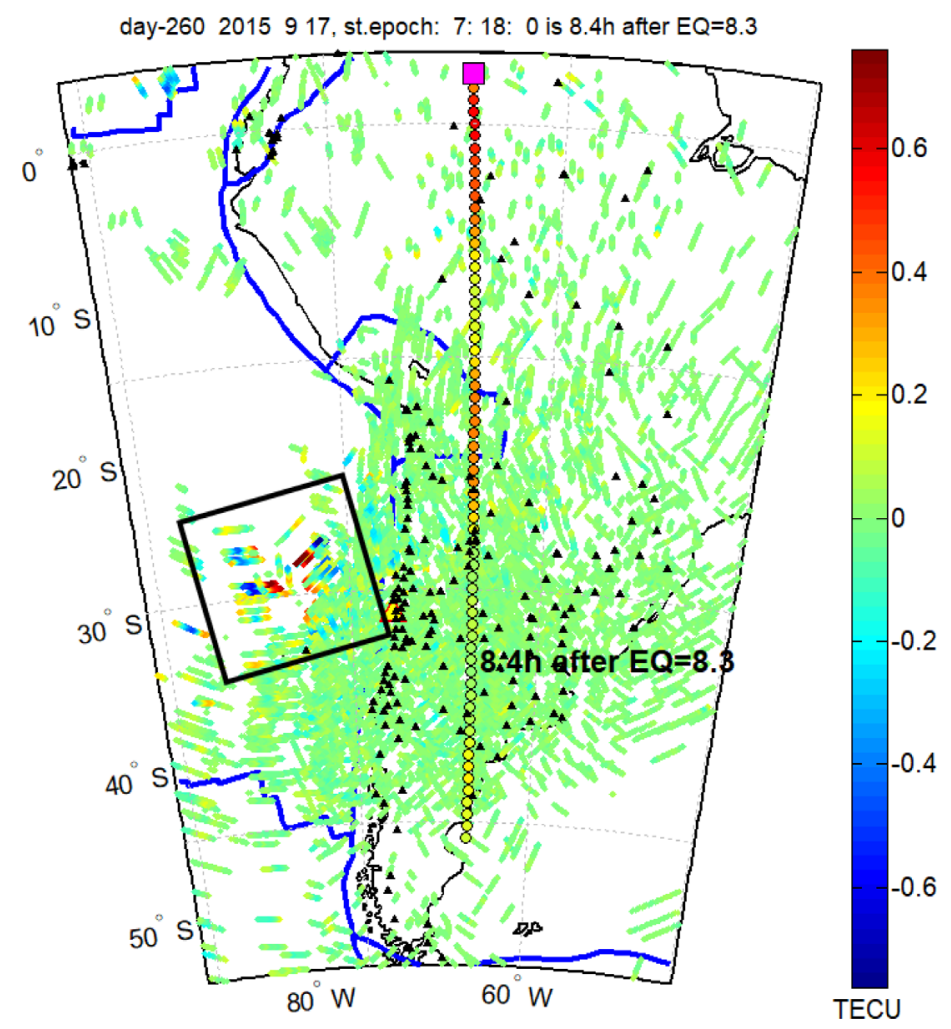

Fig. 19. The same as in Figure 11, in the morning of September 17, 2015.

in-situ LP observation can be more sensitive to such anomalies than TEC calculated along the entire way between ground stations and GNSS satellites. The POD TEC measured along the direction LEO-GNSS (Fig. 18) also appears as more fortunate than ground measurements from Figure 19, however, more factors can play a role there, like e.g., reference altitude of measurements or data filtering band.

\subsubsection{Potential Chile 2015 tsunami signature in the directly estimated 4D electron density gradient}

The combination of co-located ground-based and LEObased GNSS measurements under the ionospheric tomographic model has been a powerful approach for studying the 4D ionospheric footprint of Space Weather at global scale (Hernández-Pajares et al., 1998). Indeed, the Tomographic Ionosphere model (TOMION) (Hernández-Pajares et al., $1998,1999)$ is the baseline of the UPC VTEC GIMs produced for the International GNSS Service (IGS) since June 1st, 1998, which have been improved in comparison to their first release (Roma-Dollase et al., 2018). TOMION is directly based on the available measurements expressed in terms of voxel basis functions. The model can capture localized ionospheric electron content features, modeling properly the $4 \mathrm{D}$ components of the electron content gradients with the ionospheric-mappingfunction. Mean ED of the voxels is obtained from the ionospheric geometry-free combination $L_{\mathrm{G}-\mathrm{F}}$ of carrier phases only (see Hernández-Pajares et al., 2011). The solution is obtained thanks to the Kalman filter integrated into TOMION, treating the sun-fixed ED as a random walk and estimating the carrier phase bias (or ambiguity) as a random variable.

Very recently, an extension of the applicability of the TOMION model (multiTOMION) has been done by combining GNSS-POD LEOs-, GNSS ground- and vessel-, and DORISbased measurements with the corresponding improvement of VTEC Global Ionospheric Maps (Hernández-Pajares et al., 2020). This extension can provide a direct estimation of 4D ED gradients as a good tool for future tsunami detection and characterization, augmented with the use of LEO constellations much larger than the Swarm one, such as e.g., Spire CubeSats. The larger constellations will assure higher co-location with potential future tsunamis. TOMION model is applied in this study to the calculation of 4D ED gradient directly from the voxel-based tomography, in the analysis of Chile-Illapel EQ and the following tsunami. We have run TOMION in an extremely sensitive mode: with high horizontal resolution $\left(1^{\circ} \times 1^{\circ}\right.$ in right ascension and latitude), high temporal resolution (30 s), increased random walk noise, and the standard twolayer models suitable in ground-based tomographic modeling. Due to the lack of co-location of the Swarm constellation and other LEOs, we supported the model with the available multi-GNSS measurements from CSN, IGN, IGS, and other receivers available in this region. By applying this approach, we are able to find significant horizontal bottom ED gradients on September 16, 2015 after the EQ, following a radial pattern, which is compatible with the tsunami signature (Fig. 20b). Figure 20 a presents quite randomly distributed horizontal ED components during a similar time period of the previous day. 
a)

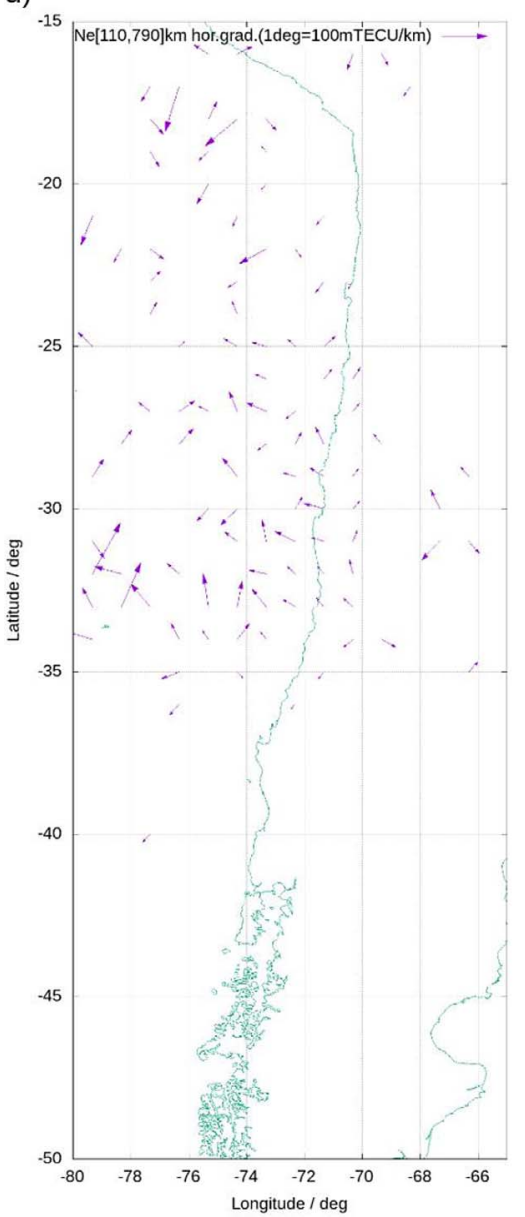

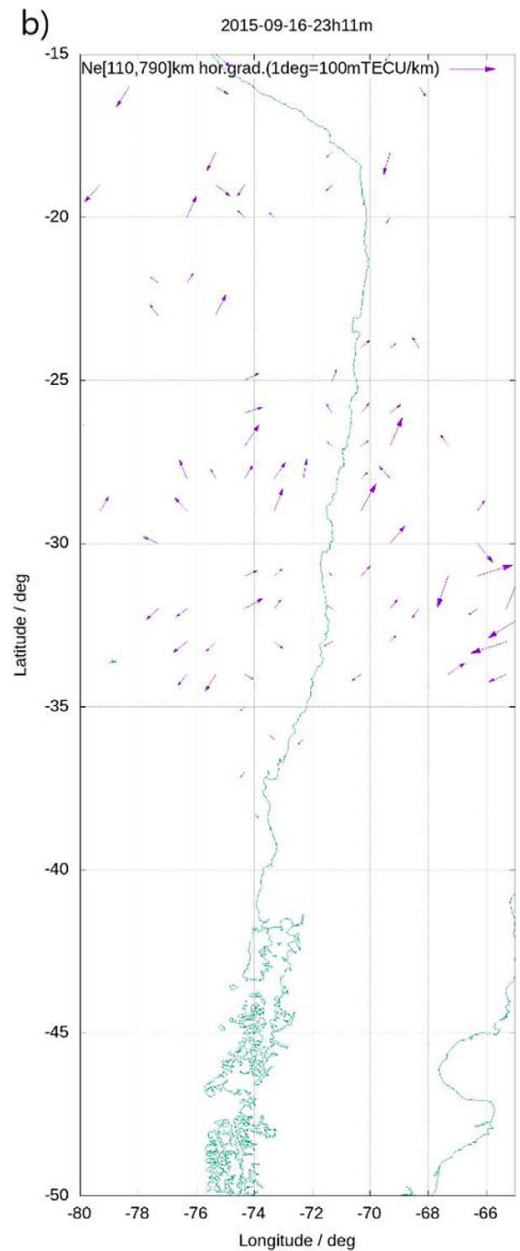

Fig. 20. Horizontal component of ED gradient corresponding to the bottom layer of voxels, the height of which ranges between 110 and $790 \mathrm{~km}$ and representing pierce points at mid-height of $450 \mathrm{~km}$, (b) during day 2015-09-16: 16.5 min after EQ main shock, and (a) 1 day before the EQ at a similar time (2015-09-15, 23:11:00), computed with TOMION from the CSN and IGN networks of ground GNSS receivers.

\subsection{Far away from the epicenter}

\subsubsection{Validation of Swarm co-seismic ionosphere disturbances (CID) detection with ionosonde data}

The purpose of this study part is to examine Digisonde and Swarm coincident observations and consider the possible connection to EQ-triggered perturbations. The investigation of simultaneous observations in the bottom side and topside ionosphere can lead to results regarding the connection between medium-scale TIDs, spread F, and topside ED gradients with the effects triggered by the EQ at various ionospheric heights. In order to achieve this goal, the first step is to ingest the Digisonde-bottom side and the Swarm in situ-topside observation in a continuous ED distribution from the height of $90 \mathrm{~km}$ up to the altitude of the Swarm satellite. To that effect, Swarm-Digisonde coincidences were identified in order to have simultaneous and co-located observations. A Swarm-Digisonde coincidence is defined as the satellite pass above an area around the Digisonde with a radius of 2.5 degrees $(\approx 250 \mathrm{~km})$. Each Swarm pass above the area of coincidence has a maximum

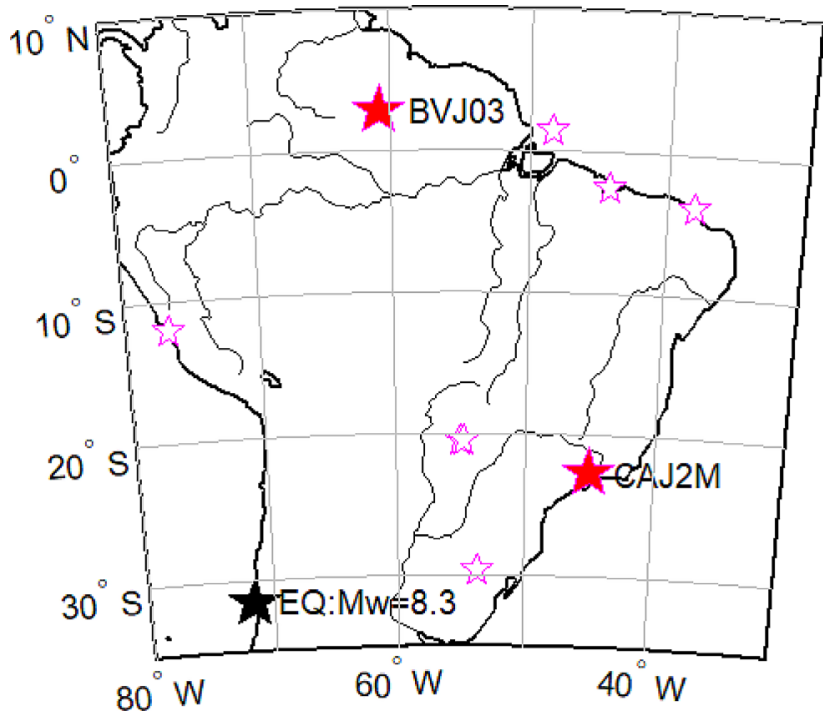

Fig. 21. Location of Boa Vista (BVJ03) and Cachoeira Paulista $(\mathrm{CAJ} 2 \mathrm{M})$ Digisondes in respect to the EQ epicenter. 


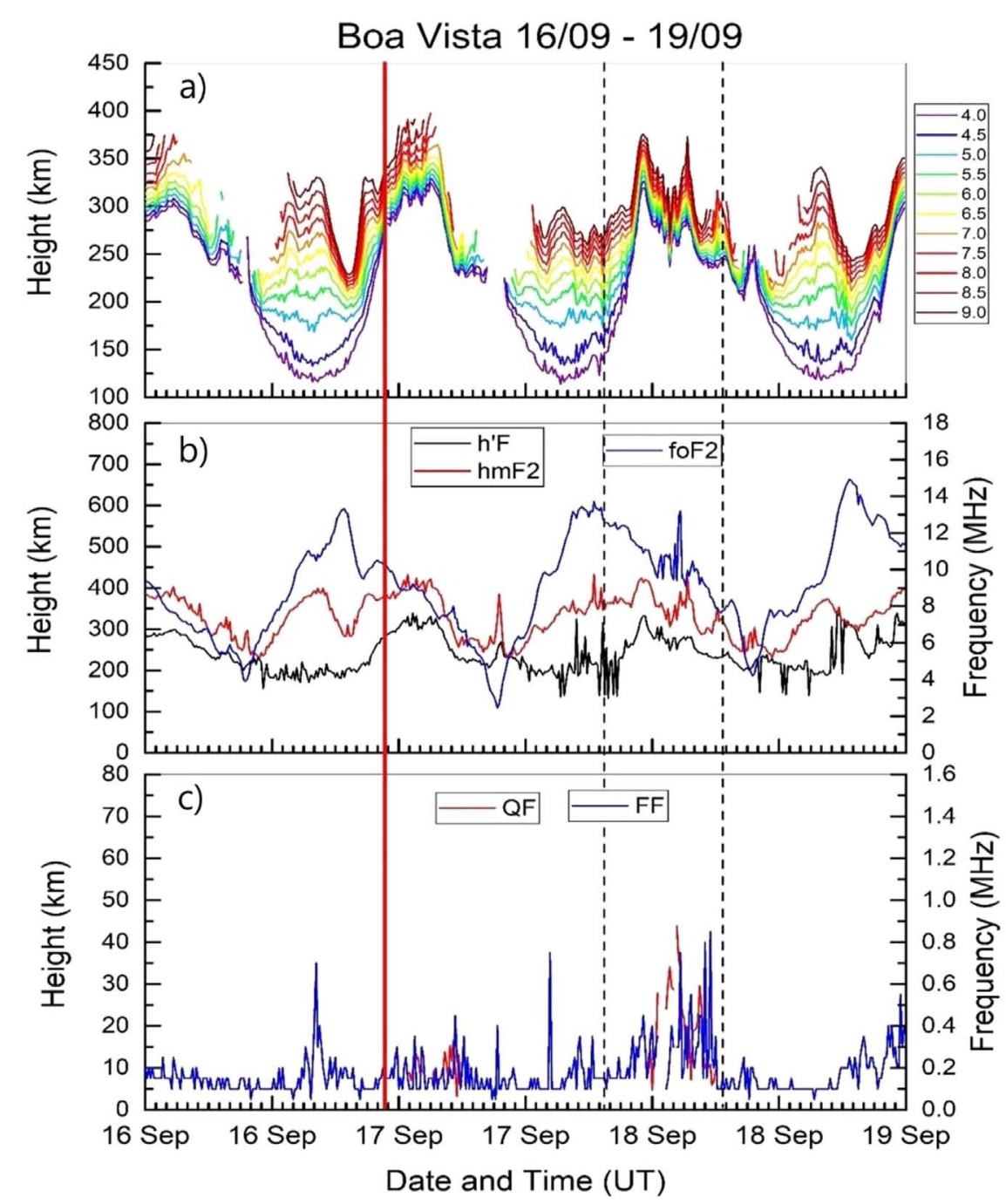

Fig. 22. Data from Boa Vista Digisonde ionograms: (a) The isoionic contour plots, (b) the critical characteristics foF2 (blue line), $h^{\prime} F$ (black line), hmF2 (red line), and (c) the spread F parameters FF (blue line) and QF (red line).

duration of $90 \mathrm{~s}$. For each coincidence, the ED profile is calculated from the bottom side ionosphere up to Swarm A altitude by applying the $\alpha-\mathrm{C}-\mathrm{SD}$ model (Belehaki et al., 2021). The model assumes that above the hmF2 height and up to the Swarm altitude, the distribution of the ionospheric ED can be approximated with an $\alpha$-Chapman function with variable scale height. The maximum $\mathrm{ED}$ at $\mathrm{hmF} 2$ measured by the Digisonde and the ED provided by Swarm LP are the two anchor points that define the shape of the ED distribution. The scale height at the hmF2 is calculated from the Digisonde bottom side profile (Huang \& Reinisch, 1996), and it is provided as an ionospheric characteristic in the SAO files (Gamache et al., 1996). The scale height at the Swarm height is calculated with the $\alpha$-Chapman function so that the boundary condition defined by the LP ED measurement at Swarm altitude is satisfied. The results are validated by comparing the reconstructed TEC with the GNSS TEC. In the vast majority of cases, the reconstructed total TEC matches with extremely high accuracy the GNSS TEC, providing strong evidence that the assumption for the $\alpha$-Chapman ED approximation in the topside part between the hmF2 and the Swarm altitude is a valid one (Belehaki et al., 2021).

In this study, the $\alpha-C-S D$ model is applied to reconstruct the ED profile during Swarm A passes over Digisondes in a wide region around the EQ epicenter. The variability of the ionospheric characteristics in the bottom side and topside ionosphere is considered as an indicator for lower and upper atmosphere interactions. Based on the abovementioned criteria, there are no coincident Swarm data with Cachoeira Paulista station. Therefore, the results are presented for two Swarm A passes over the closest Boa Vista Digisonde, several hours after the main EQ shock. Swarm A passes over the Digisonde occurred 20 and $32 \mathrm{~h}$ after the mainshock. The location of the two Digisondes in respect to the EQ epicenter is given in Figure 21.

Figure 22 presents Boa Vista Digisonde recordings from September 16, 2015 to September 18, 2015 as isoionic contour 
(a)

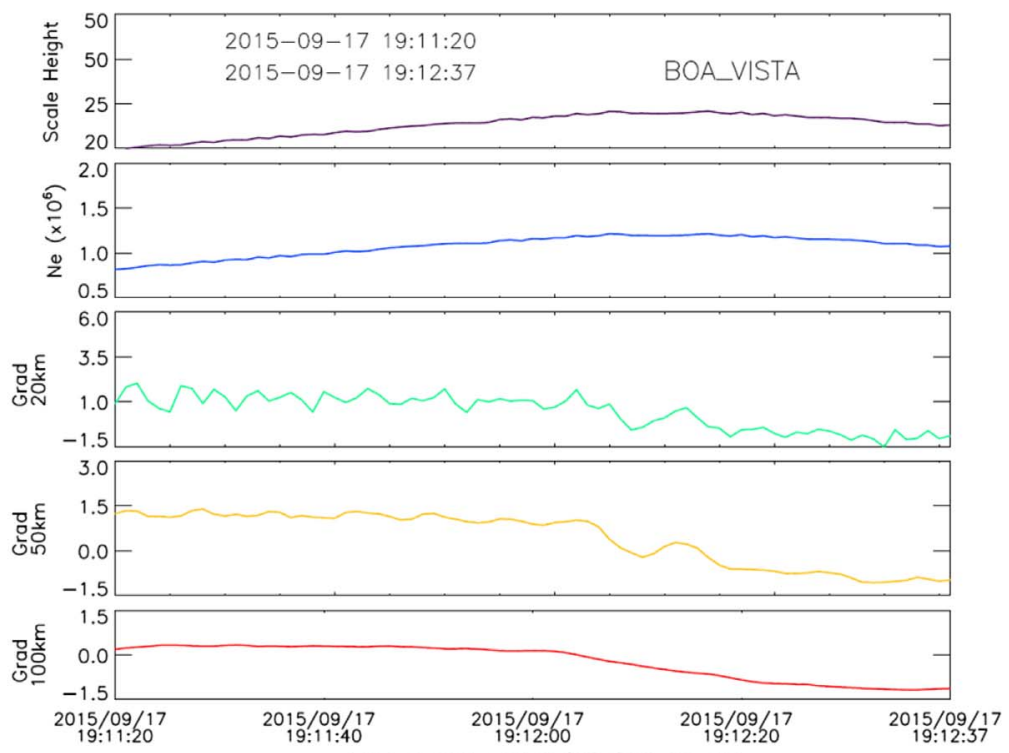

(b)

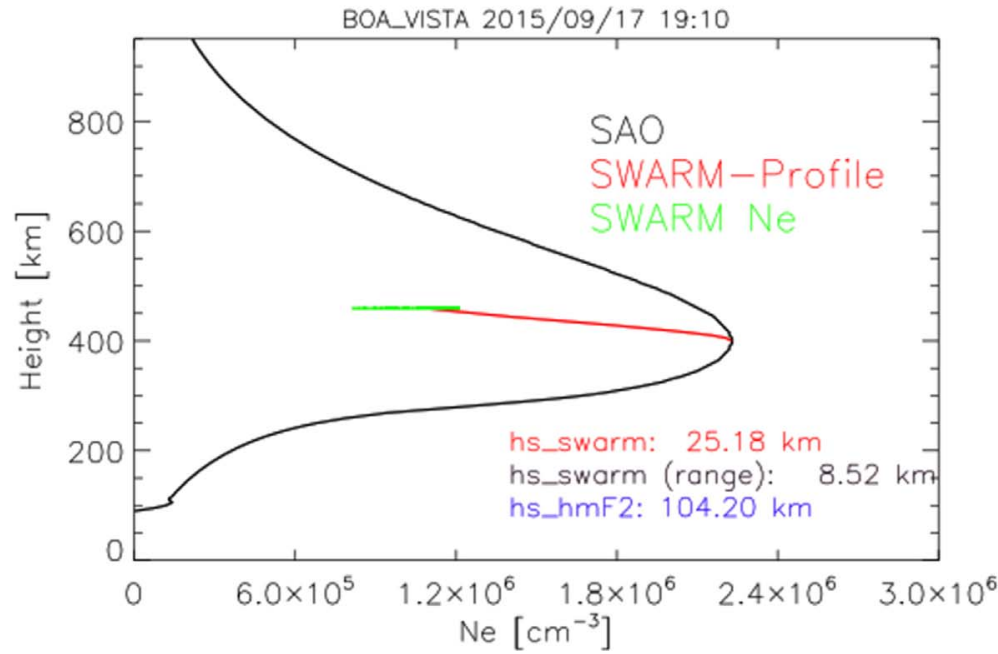

Fig. 23. Swarm and Digisonde observations on September 17, 2015 (a) the topside scale-height at Swarm altitude calculated with the $\alpha$-C-SD model, the Swarm electron density Ne and the Swarm irregularity indices gradient ED at $20 \mathrm{~km}, 50 \mathrm{~km}$ and $100 \mathrm{~km}$ during the $90 \mathrm{~s}$ of the satellite pass over the Digisonde from 19:11:19 UTC to 19:12:37 UTC. (b) The Digisonde electron density profile and the reconstructed topside electron density with the $\alpha$-C-SD model in a red color trace; the green color trace represents the insitu Swarm ED observed during the Swarm pass over the Digisonde.

plots and as time-plots of the following ionospheric characteristics:

- The F2 layer critical frequency, foF2

- The peak height of the F2 layer, hmF2

- The minimum virtual height of the $\mathrm{F}$ layer, $\mathrm{h}^{\prime} \mathrm{F}$

- The range spread of F-layer, QF

- The frequency spread between fxF2 and fxI, FF

All the ionograms used to extract the ionospheric characteristics were manually scaled for higher accuracy. The cadence of the vertical incidence soundings in Boa Vista Digisonde is $5 \mathrm{~min}$. The vertical solid line in Figure 22 corresponds to the occurrence time of the main EQ shock, while the vertical dashed lines correspond to the Swarm A passes over the Boa Vista Digisonde coincidence area.
Shortly after the EQ, the bottom side ionosphere shows signatures of irregularities since spread $\mathrm{F}$ (FF and $\mathrm{QF}$ ) is recorded in the ionograms consequently for at least $8 \mathrm{~h}$, from 23:00 UTC on September 16, 2015 to 09:00 UTC on September 17, 2015. During this interval, signatures of medium-scaled TIDs (MSTIDs) are observed in the isoionic contours (Fig. 22a). The next intensification of irregularities appears from around 20:00 UTC on September 17, 2015 to around 06:00 UTC on September 18, 2015, manifested as highfrequency fluctuations in the isoionic contours, as strong fluctuations in $\mathrm{h}^{\prime} \mathrm{F}$ and $\mathrm{hmF} 2$ and high values of $\mathrm{QF}$ and $\mathrm{FF}$ characteristics.

The data collected during the first Swarm A pass over Boa Vista Digisonde on September 17, 2015 from 19:11:20 UTC to 19:12:37 UTC are shown in Figure 23a with the following order from top to bottom: the scale height at Swarm A altitude 
(a)

(b)
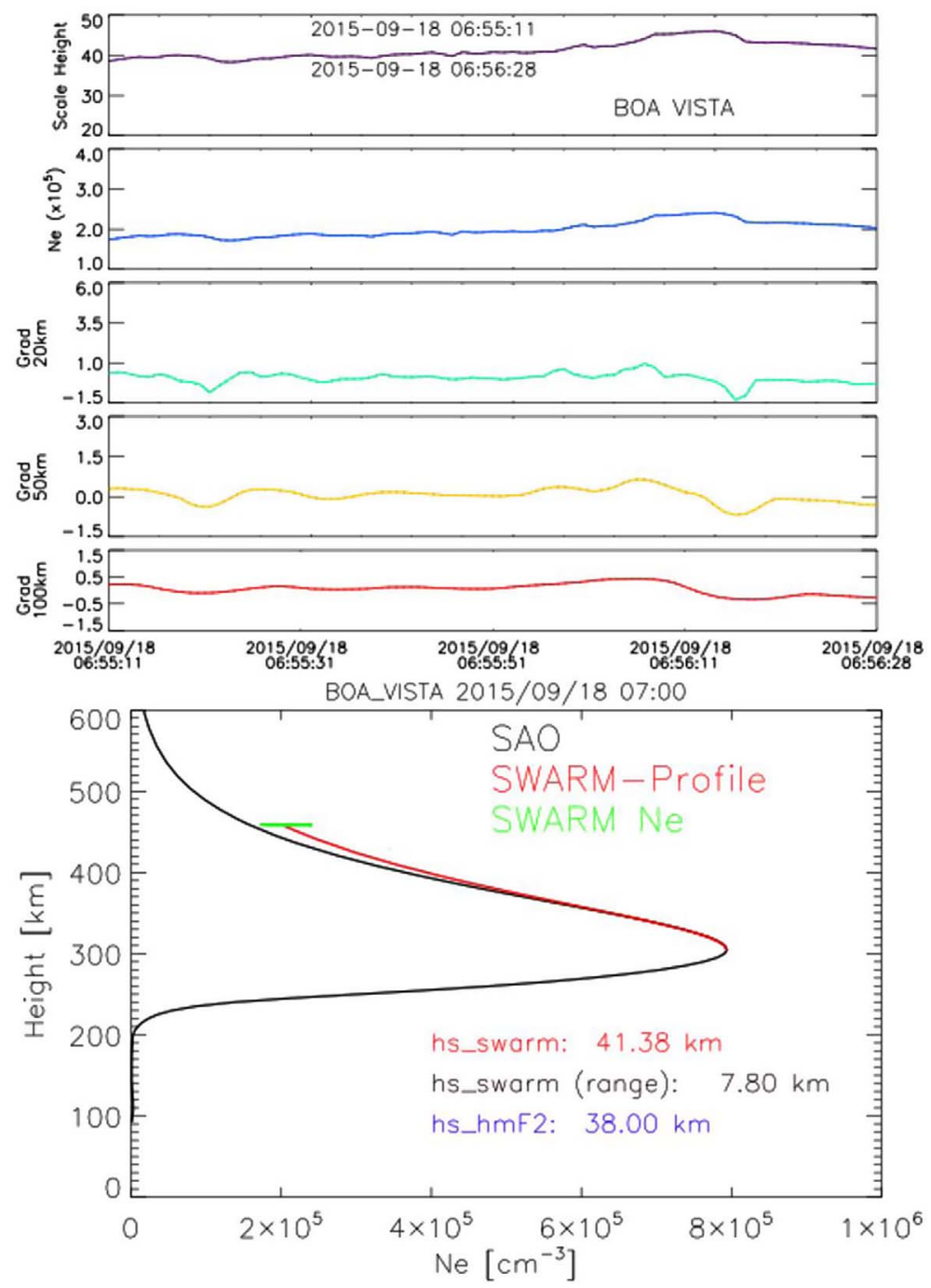

Fig. 24. Same as Figure 23 for the satellite pass over Bua Vista Digisonde which occurred from 06:55:11 UTC to 06:56:28 UTC on September $18,2015$.

calculated with the $\alpha$-C-SD model, the in-situ ED from Swarm LP experiment and the Swarm A irregularity indices of gradient ED at $20 \mathrm{~km}, 50 \mathrm{~km}$, and $100 \mathrm{~km}$ (Jin et al., 2019). The Digisonde ED profile (SAO profile) and the topside ED profile reconstructed with the $\alpha-\mathrm{C}-\mathrm{SD}$ model in a red color trace (Swarm profile) are shown in Figure $23 \mathrm{~b}$ together with the insitu Swarm ED data in green color, observed during the Swarm A pass over the Digisonde. It should be noted here that the Digisonde ED profile is calculated from ionogram inversion only up to the hmF2 height. Its topside part is the result of the Huang-Reinisch model (Huang \& Reinisch, 2001), which assumes a constant scale height. However, it should be taken into account that this is only an approximation and it is shown here as a reference. During this short duration of Swarm A pass over the Digisonde, the difference between the SAO profile and the Swarm reconstructed profile is very pronounced. This is the result of the different scale heights. The SAO profile reconstruction assumes that the scale height in the topside is constant and equal to the scale height at $\mathrm{hmF} 2$. The Swarm profile reconstruction assumes that the scale height varies so that the electron density calculated with the $\alpha$-Chapman approximation becomes equal to the measured electron density from Swarm LP. The SAO scale height at $\mathrm{hmF} 2$ is $104.20 \mathrm{~km}$, whereas the scale heights calculated with the Swarm reconstruction $\alpha-C-S D$ model get values in the range of $(25.18 \pm 8.52) \mathrm{km}$ during the $90 \mathrm{~s}$ of Swarm pass over the Digisonde. This large decrease of the topside scale height indicates that, at least locally, the electron density above the hmF2 and up to $\sim 450 \mathrm{~km}$ decreases fast with altitude. It must be noted that this local decrease in the topside ED is observed simultaneously with fluctuations in the virtual scale height of the $\mathrm{F}$ layer and in the isoionic contour plots, which might be indicative of MSTIDs in the bottom side ionosphere.

During the $90 \mathrm{~s}$ of coincidence, the topside Grad Ne index at the range of $20 \mathrm{~km}$ shows systematic fluctuations, which faint at larger ranges, as seen in the topside Grad $\mathrm{Ne}$ index at $100 \mathrm{~km}$. These observations indicate upward propagation of plasma irregularities which break into small structures in the topside ionosphere (Kuo et al., 1998; Eltrass et al., 2014, 2016). These waves may be initiated by the numerous aftershocks that 


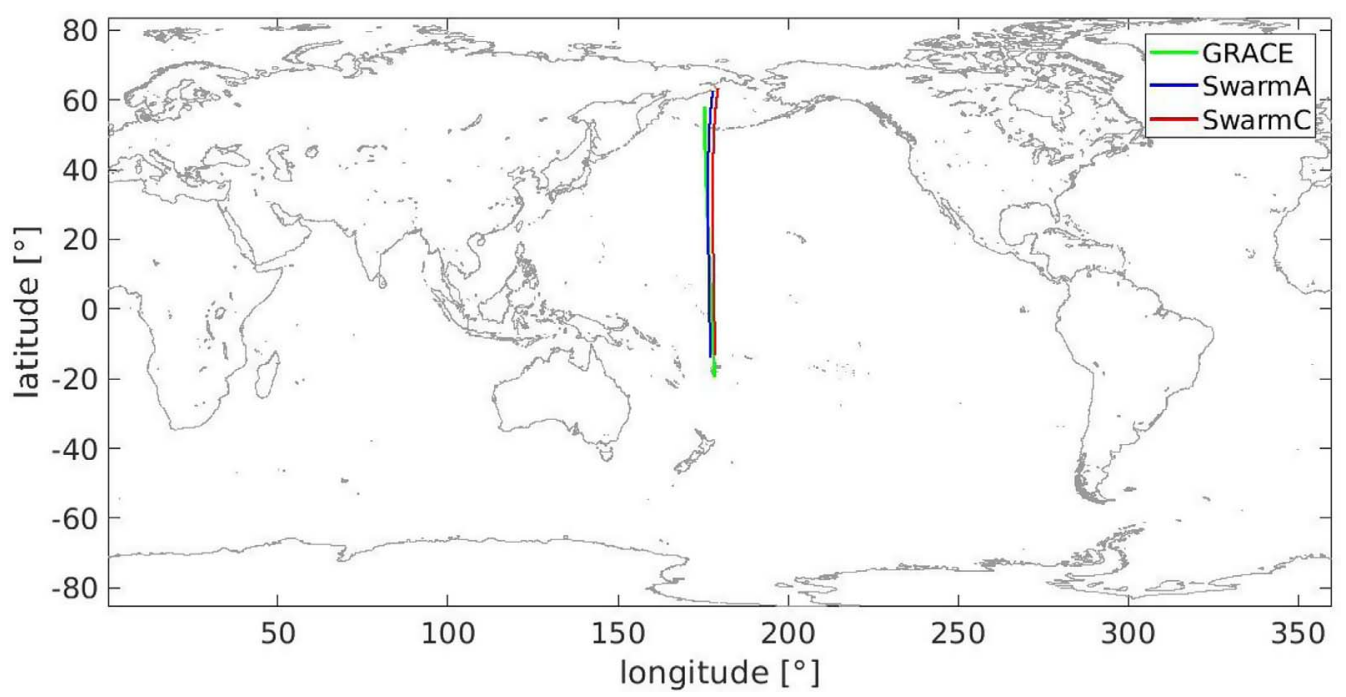

Fig. 25. Groundtrack of the Swarm A and C satellites plotted with blue and red color, respectively, for the time between 15:15 UT and 15:35 UT on September 17, 2015 and the groundtrack of the GRACE satellites plotted in green color for the time span between 15:30 UT and 15:50 UT on September 17, 2015.
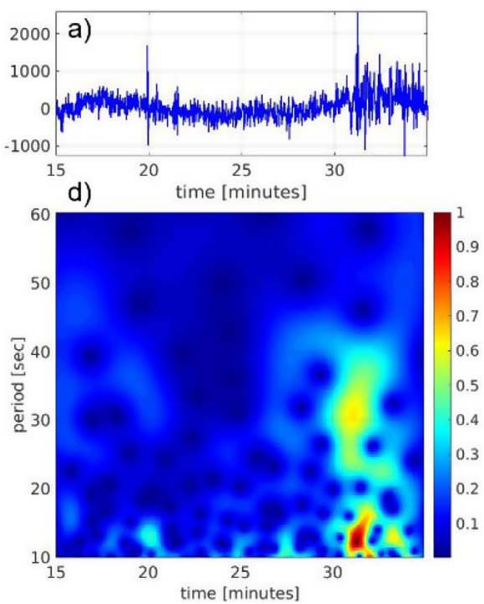
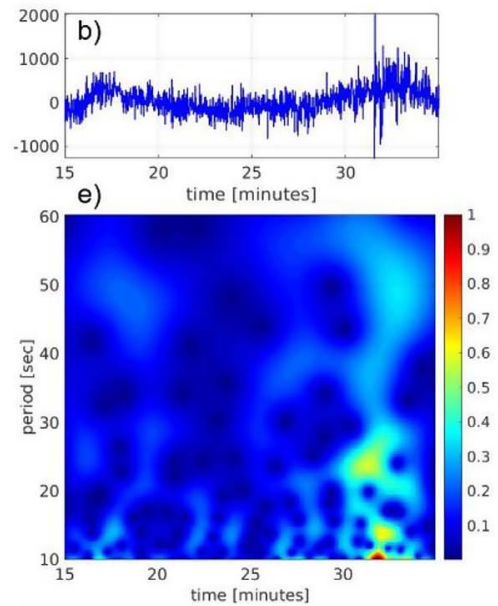

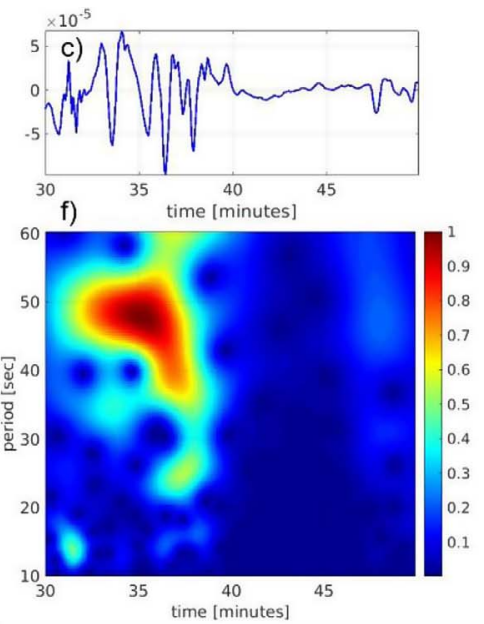

Fig. 26. Scalograms of the differenced LP observations of Swarm A and C and the differenced Ka-band observations of GRACE for a selected time interval of Tsunami crossings.

occurred for the whole day after the mainshock (as presented in Fig. 1), produced by the conversion of the crust oscillations into acoustic waves and then in variations in the ionospheric electron density.

The second Swarm A pass over Boa Vista Digisonde occurred $32 \mathrm{~h}$ after the main EQ shock, from 0655:11 UTC to $0656: 28$ UTC on September 18, 2015. As concluded from the inspection of Figure 22, this second pass occurred when the ionosphere was relatively unperturbed since the $\mathrm{QF}$ and FF indices were close to zero and the ionospheric characteristics $\mathrm{h}^{\prime} \mathrm{F}$ and $\mathrm{hmF} 2$ did not show any fluctuations. The top panel (Fig. 24a) provides the time plots of the characteristics and calculated parameters during the $90 \mathrm{~s}$. of Swarm A pass over the Digisonde. The lower panel (Fig. 24b) presents the ED profile from the Digisonde (SAO profile) and from the $\alpha$-C-SD model (Swarm profile) together with the insitu ED data from Swarm LP, as in Figure 23. Some very weak disturbances are recorded during the Swarm A pass over the Digisonde, which are also reflected in the scale height.

For this second Swarm A pass over the Boa Vista Digisonde, the reconstructed topside ED profile agrees relatively well with the Digisonde reconstructed ED profile. The SAO scale height at hmF2 is $38.0 \mathrm{~km}$, whereas the scale heights calculated with the Swarm reconstruction model get values in the range of $(41.38 \pm 7.80) \mathrm{km}$ during the $90 \mathrm{~s}$ of Swarm pass over the Digisonde. In other words, the SAO scale height is within the range of values of the topside scale height. This agreement indicates that the ionospheric density in the layer above $\mathrm{hmF} 2$ 
and up to $\sim 450 \mathrm{~km}$ is relatively stable. The ionospheric conditions during this second pass are very different in the first Swarm pass over Boa Vista, where the reconstructed topside ED profile differs significantly from the Digisonde reconstructed ED profile, providing an indication that the proposed method is efficient for the detection of irregularities in the topside ionosphere.

\subsubsection{TIDs detection on board of GRACE and Swarm in the ocean area}

The GRACE mission is equipped with Ka-Band and $\mathrm{K}-\mathrm{Band}$ ranging systems (KBR). The system of KBR tracking measures the distance between the two GRACE satellites (satellite-to-satellite tracking - SST) with very high precision. Each of the two satellites transmits a carrier signal and measures the phase of the carrier generated by the other satellite relative to the signal it is transmitting. The sum of the phases generated is proportional to the range change between the satellites, while the phase variation due to long-term instability in each clock cancels out. The KBR system can measure the range (with a bias) to the $\mu \mathrm{m}$ level. However, the observations suffer from the ionospheric delay caused by the electrons between the transmitting satellite $\mathrm{T}$ and the receiving satellite $\mathrm{R}$. TIDs which are induced by tsunamis cause changes in ED which can be observed by the GRACE mission, in case when the satellite passes these TIDs. The along-track measurements of selected observation techniques detecting the gravity wave induced by EQ or tsunami and, thus, variations due to TIDs, can be analyzed by means of continuous wavelet transform (DWT) (Schmidt, 2001). In order to determine whether these signal variations are present in the observations from Swarm and GRACE at the time when they pass the tsunami region far from the epicenter, a two-step procedure is applied:

1. In a first step, a tsunami propagation model is used to determine the approximate time when the satellites crossed the tsunami in the Pacific Ocean.

2. In a second step, the LP observations measured during the tsunami crossing are analyzed for signal variations with periods of 15-30 s. For this purpose, a wavelet transform is used.

There are co-locations of the Swarm and GRACE satellites over the region where the tsunami was spreading $17 \mathrm{~h}$ after the mainshock, in the time between 15:15 and 15:50 UTC.

Using the wavelet transform the ED observations of the LP sensors on Swarm A, and C satellites, as well as the K/Ka-Band observations from GRACE are analyzed for the time periods shown as co-located in Figure 25. As the aim of this study is to detect the TID's in the observations of ED, the change of the signal as the centered differences

$$
f(t)=\frac{1}{2 h}(y(t-\Delta t)-y(t+\Delta t))
$$

of the observations are computed at first in order to eliminate any biases from the signal. In equation (1) $y(t)$ is the observed $\mathrm{ED}$ at the time $t$ and $\Delta t$ is the temporal sampling of the observed data; in case of the Swarm satellites A, B and C the sampling interval is fixed to $\Delta t=1 \mathrm{~s}$ for the LP observations. The KBR observations of GRACE are initially sampled with a temporal distance of $\Delta t=5 \mathrm{~s}$. Figures 26a-26c) shows the centered differences of Swarm A and Swarm C LP data and the GRACE KBR instrument. The scalograms calculated for LP ED observations from the satellites Swarm A and C co-located with the tsunami between 15:15 UTC and 15:35 UTC on September 17, 2015 are presented in Figures 26d-26e. As it can be seen from the scalograms, signal variations with significant periods around $15 \mathrm{~s}$ are detectable, which may be related to the TIDs induced by the tsunami (Yang et al., 2019). Since the Swarm satellites A and C follow approximately one after the other, with a small shift in the ground tracks (cf. Fig. 25), the two scalograms show similar characteristics. Differences in the scalograms may result from their distance in the orbit and thus, from a shift of the phase of the TID, as well as from slightly different angles at which the satellite crosses the TID. The GRACE satellites cross the tsunami wave some min after the two Swarm satellites, i.e., between 15:30 UTC and 15:50 UTC. Figure 26f shows the scalogram of the differenced GRACE K/Ka-band observations, where signal variations with periods of $10 \mathrm{~s}$ and $30 \mathrm{~s}$ show significant energy distribution, similar to those of the two Swarm satellites. The periods in the range of $15 \mathrm{sec}$ appear in all scalograms at minute 33, as well as the periods in the range of $25 \mathrm{~s}$, which appear in Figures 26d-26e at the same time and in $26 \mathrm{f}$ with a time offset, should be emphasized at this point. The differences visible in the scalograms of the different satellites may occur due to the different altitudes and may be caused by different times and directions of propagation.

\section{Summary and conclusions}

The objective of this work was to demonstrate the synergistic effect of a wider scope of data sources and techniques worth considering together, as well as a wider spatiotemporal window analyzing seismically triggered changes in the ionosphere and changes correlated with tsunami. One general conclusion referring to the data is that LEO satellite data have a notably wider spatial range with respect to ground GNSS, and this advantage should be exploited. The second observation related to the data is that the more data, the lower uncertainty and wider the scope of different complementary observations. The general conclusion referring to the techniques is that filtering and spectral analysis play crucial role with respect to ground and especially LEO data, as the ionospheric signals are composed of many externally (Sun) and internally induced (Earth) anomalies. The general conclusion referring to spatio-temporal issues is that focusing only on the local dense GNSS network and close vicinity of mainshock significantly limits our knowledge about composed coupling processes between the lithosphere and ionosphere. The very detailed analysis of shape and velocities of TIDs after Tohoku EQ/tsunami in 2011, based on 1200 Japanese GEONET stations, cannot be repeated with the same precision here, as the number of used Chilean and Argentinian stations is around 200 and the analyzed region is larger. Nevertheless, the extension of the observation time and data scope gives us a very interesting preliminary inspection of the most promising timeframes and directions of future research. 
Ground GNSS data have shown many different responses of seismic activity to the ionosphere, including ionospheric anomalies before the mainshock that have speeds around $0.3 \mathrm{~km} / \mathrm{s}$, clear and faster (around $0.5-0.6 \mathrm{~km} / \mathrm{s}$ ) response to the mainshock $\left(M_{w}=8.3\right)$, as well as post-seismic disturbances, presumably also related with the tsunami. The traveling character of these disturbances and their relation with seismicity are evident in the keograms in Section 3.1.3. Swarm along-track data also reveals ionospheric anomalies of a small period $(<500 \mathrm{~km}$ along the track), and their sizes and specific spectral patterns can be found by spectral analysis. The inspection of ground GNSS data supplies a very reliable validation for the disturbed Swarm signals, as selected Swarm disturbances are spatiotemporally consistent with TIDs clearly seen in ground GNSS data (e.g. Fig. 11). Therefore the spectral patterns of Swarm disturbances in ED and POD TEC are especially worth further investigation and comparison with ground GNSS for different EQ/tsunami events.

The combined analysis of coincident observations recorded over the region affected by Chile-Illapel EQ, from ground-based ionosonde sounders and the Swarm LP instrument was carried out in Section 3.2.1 in order to understand the lower and upper atmosphere coupling process. Disturbances detected with ground-based ionograms were classified as medium scale TIDs, frequency spread-F, and range spread F. Swarm A detects coherent disturbances as highly variable gradients in the ED and highly variable scale height. This observation provides evidence of ED irregularities extended from the bottom side to the lower altitudes of the topside ionosphere. Swarm A detects coherent disturbances as variable gradients in the ED and variable scale height. This observation indicates upward propagation of plasma irregularities which break into small structures in the topside ionosphere, a mechanism for the cascading of ionospheric irregularities proposed by Kuo et al. (1998), Eltrass et al. (2014, 2016). The results indicate that although Swarm LP can detect in situ plasma perturbations, the simultaneous analysis of Digisonde and Swarm coincident data provide an improved nowcasting information for plasma disturbances triggered from the bottom side ionosphere and consequently an improved characterization of the whole ionosphere - lower atmosphere - lithosphere dynamics.

Simultaneous observation of the tsunami-induced TIDs on different satellites and the study of the horizontal coupling processes can determine the direction of propagation of the tsunami and its impact on the coastline. Section 3.2.2 describes the application of the wavelet transform, and similar signatures with short period lengths detected in the K/Ka-band observations of GRACE and in Swarm LP observations (altitude $450 \mathrm{~km}$ ), in time of Chile-Illapel tsunami propagation. The satellites of GRACE and Swarm missions flew successively over the tsunami region. The analysis of in-situ observations from the satellites can be used to determine the position of the tsunami as it propagates across the ocean. The roadmap studies provided the first opportunity to observe the tsunamiinduced gravity waves in the ionosphere, however, their periods need more further work to be better confirmed.

The velocities of the detected seismically triggered TIDs have been analyzed in Section 3.1.2 by the ADDTID method. The multi-TID blind analysis by ADDTID is done from around $1 \mathrm{~h}$ before the mainshock to $1 \mathrm{~h}$ after and confirms the predominant concentration of seismic TIDs in the north-east direction from the epicenter. This is consistent with keograms and scatters representations of TIDs in Section 3.1.3. Nevertheless, there is also an evident increase of TID occurrence westerly from the epicenter, as detected by ADDTID and in the scatter plots of $L_{\mathrm{G}-\mathrm{F}}$, and some of them can be related to the tsunami, due not only to counter direction regarding the epicenter but also to the correlation of the increased velocity with increased sea depth. EQ/tsunami compatible ionospheric disturbances located westerly from the epicenter, over the ocean, have also been detected in the 4D ED gradient, directly based on the voxel-based tomography model, as summarized in Section 3.1.4.

Dense ground GNSS network availability is limited to a few regions on the globe. Swarm and other LEO satellite data, in turn, are globally distributed. Additionally, due to the recent developments, the usage of GNSS receivers will be possible very soon, on board tens or even hundreds of CubeSats developed for ionospheric sounding. Therefore, the detection of TIDs from the POD GNSS receiver onboard the LEOs and CubeSats, or from the other instruments (LP, KBR) can be especially useful for the detection of ionospheric responses to EQs and tsunami. The spectral decomposition presented in Sections 3.1.3 and 3.2.2 can help in the analysis of short along-track signals. The potential warning obtained from the LEOs can then be further analyzed in a second prompt round of EQ/tsunami confirmation and characterization. This can be done using a combination of ground GNSS data, ionosondes, and 4D ED gradient techniques. Therefore, current preliminary studies can be helpful in the creation of the system of wide-area detection of seismic ionospheric anomalies for prompt detection of tsunamis.

Acknowledgements. The study was funded from COSTO project, which has received funding from the ESA contract $4000126730 / 19 / \mathrm{NL} / \mathrm{IA}$, in the framework of the "Swarm+ Coupling: High-Low Atmosphere Interactions" Call. Anna Belehaki acknowledges financial support provided by the AFRL grant award FA9550-19-1-7019. The editor thanks Dimitar Ouzounov and Sergey Pulinets for their assistance in evaluating this paper.

\section{References}

Afraimovich EL, Ding F, Kiryushkin V, Astafyeva E, Jin SG, Sankov V. 2010. TEC response to the 2008 Wenchuan earthquake in comparison with other strong earthquakes. Int J Remote Sens 31(13): 3601-3613. https://doi.org/10.1080/01431161003727747.

Akhoondzadeh M. 2019. Seismo-magnetic field anomalies detection using Swarm Satellites (Alpha, Bravo and Charlie). Int Arch Photogramm Remote Sens Spatial Inf Sci XLII-4/W18: 45-49. https://doi.org/10.5194/isprs-archives-XLII-4-W18-45-2019.

Akhoondzadeh M, Parrot M, Saradjian MR. 2010. Electron and ion density variations before strong earthquakes $(M>6.0)$ using DEMETER and GPS data. Nat Hazards Earth Syst Sci 10(1): 7-18. https://doi.org/10.5194/nhess-10-7-2010.

Anagnostopoulos G, Vassiliadis E, Pulinets S. 2012. Characteristics of flux-time profiles, temporal evolution, and spatial distribution of radiation-belt electron precipitation bursts in the upper ionosphere before great and giant earthquakes. Ann Geophys 55: 21-36. 
Artru J, Farges T, Lognonné P. 2004. Acoustic waves generated from seismic surface waves: propagation properties determined from Doppler sounding observations and normal-mode modelling. Geophys J Int 158(3): 1067-1077. https://doi.org/10.1111/ j.1365-246X.2004.02377.x.

Artru J, Dučić V, Kanamori H, Lognonné P, Murakami M. 2005. Ionospheric detection of gravity waves induced by tsunamis. Geophys J Int 160(3): 840-848. https://doi.org/10.1111/j.1365246X.2005.02552.x.

Astafyeva E, Shults K. 2019. Ionospheric GNSS imagery of seismic source: possibilities, difficulties, and challenges. J Geophys Res Space Phys 124: 534-543. https://doi.org/10.1029/2018JA026107.

Astafyeva E, Shalimov S, Olshanskaya E, Lognonne P. 2013. Ionospheric response to earthquakes of different magnitudes: larger quakes perturb the ionosphere stronger and longer. Geophys Res Lett 40: 1675-1681. https://doi.org/10.1002/grl.50398.

Azeem I, Vadas SL, Crowley G, Makela JJ. 2017. Traveling ionospheric disturbances over the United States induced by gravity waves from the 2011 Tohoku tsunami and comparison with gravity wave dissipative theory. J Geophys Res Space Phys 122: 3430-3447. https://doi.org/10.1002/2016JA023659.

Belehaki A, Tsagouri I, Paouris E. 2021. Characteristics of the effective scale height in the topside ionosphere extracted from Swarm A and Digisonde observations [Preprint]. https://doi.org/ 10.1002/ essoar.10508484.2.

Chou M-Y, Cherniak I, Lin CCH, Pedatella NM. 2020. The persistent ionospheric responses over Japan after the impact of the 2011 Tohoku earthquake. Space Weather 18: e2019SW002302. https://doi.org/10.1029/2019SW002302.

Chum J, Liu JY, Laštovička J, Fišer J, Mošna Z, Baše J, Sun YY. 2016. Ionospheric signatures of the April 25, 2015 Nepal earthquake and the relative role of compression and advection for Doppler sounding of infrasound in the ionosphere. Earth Planets Space 68: 24. https://doi.org/10.1186/s40623-016-0401-9.

Coisson P, Lognonné P, Walwer D, Rolland LM. 2015. First tsunami gravity wave detection in ionospheric radio occultation data. Earth Space Sci 2: 125-133. https://doi.org/10.1002/2014EA000054.

De Santis A, Marchetti D, Pavón-Carrasco FJ, Cianchini G, Perrone L, et al. 2019. Precursory worldwide signatures of earthquake occurrences on Swarm satellite data. Sci Rep 9: 20287. https://doi. org/10.1038/s41598-019-56599-1.

Diego P, Coco I, Bertello I, Candidi M, Ubertini P. 2019. Ionospheric plasma density measurements by Swarm Langmuir probes: limitations and possible corrections. Ann Geophys Discuss. https://doi.org/10.5194/angeo-2019-136.

Dučić V, Artru J, Lognonné P. 2003. Ionospheric remote sensing of the Denali Earthquake Rayleigh surface waves. Geophys Res Lett 30(18): 1951. https://doi.org/10.1029/2003GL017812.

Eltrass A, Mahmoudian A, Scales WA, de Larquier S, Ruohoniemi JM, Baker JBH, Greenwald RA, Erickson PJ. 2014. Investigation of the temperature gradient instability as the source of midlatitude quiet time decameter-scale ionospheric irregularities: 2. Linear analysis. J Geophys Res Space Phys 119: 4882-4893. https://doi. org/10.1002/2013JA019644.

Eltrass A, Scales WA, Erickson PJ, Ruohoniemi JM, Baker JBH. 2016. Investigation of the role of plasma wave cascading processes in the formation of midlatitude irregularities utilizing GPS and radar observations. Radio Sci 51: 836-851. https://doi.org/ 10.1002/2015RS005790.

Galkin IA, Khmyrov GM, Kozlov A, Reinisch BW, Huang X, Kitrosser DF. 2006. Ionosonde networking, databasing, and Web serving. Radio Sci 41: RS5S33. https://doi.org/10.1029/ 2005RS003384.
Galvan DA, Komjathy A, Hickey MP, Stephens P, Snively J, Tony Song Y, Butala MD, Mannucci AJ. 2012. Ionospheric signatures of Tohoku-Oki tsunami of March 11, 2011: Model comparisons near the epicenter. Radio Sci 41: RS5S33. https://doi.org/10.1029/ 2005RS003384.

Gamache RR, Galkin IA, Reinisch BW. 1996. A database record structure for Ionogram Data. Rep. UMLCAR 96-01, Cent. for Atmos. Res., Univ. of Mass.-Lowell, Lowell, MA.

Garcia R, Crespon F, Ducic V, Lognonne P. 2005. Three-dimensional ionospheric tomography of post-seismic pertubations produced by the Denali earthquake from GPS data. Geophys J Int 163: 10491064. https://doi.org/10.1111/j.1365-246X.2005.02775.x.

Garcia RF, Doornbos E, Bruinsma S, Hebert H. 2014. Atmospheric gravity waves due to the Tohoku-Oki tsunami observed in the thermosphere by GOCE. J Geophys Res Atmos 119: 4498-4506. https://doi.org/10.1002/2013JD021120.

Goto SI, Uchida R, Igarashi K, Chen CH, Kao M, Umeno K. 2019. Preseismic ionospheric anomalies detected before the 2016 Taiwan earthquake. J Geophys Res Space Phys 124: 9239-9252. https://doi.org/10.1029/2019JA026640.

Grawe MA, Makela JJ. 2017. Observation of tsunami-generated ionospheric signatures over hawaii caused by the 16 september 2015 illapel earthquake. J Geophys Res Space Phys 122(1): 1128 1136. https://doi.org/10.1002/2016JA023228.

Harris FJ. 1978. On the Use of Windows for Harmonic Analysis with the Discrete Fourier Transform. Proc IEEE 66: 66-67. https://doi. org/10.1109/PROC.1978.10837.

He L, Heki K. 2016. Three-dimensional distribution of ionospheric anomalies prior to three large earthquakes in Chile. Geophys Res Lett 43: https://doi.org/10.1002/2016GL069863.

Heki K, Enomoto Y. 2013. Preseismic ionospheric electron enhancements revisited. J Geophys Res Space Phys 118: 66186626. https://doi.org/10.1002/jgra.50578.

Heki K, Ping J. 2005. Directivity and apparent velocity of the coseismic ionospheric disturbances observed with a dense GPS array. Earth Planet Sci Lett 236(3): 845-855. https://doi.org/10.1016/j. eps1.2005.06.010.

Heki K, Otsuka Y, Choosakul N, Hemmakorn N, Komolmis T, Maruyama T. 2006. Detection of ruptures of Andaman fault segments in the 2004 great Sumatra earthquake with coseismic ionospheric disturbances. J Geophys Res Solid Earth 111(B9): B09313. https://doi.org/10.1029/2005JB004202.

Hernández-Pajares M, Juan JM, Sanz J, Solé JG. 1998. Global observation of the ionospheric electronic response to solar events using ground and LEO GPS data. J Geophys Res Space Phys 103(A9): 20789-20796. https://doi.org/10.1029/98JA01272.

Hernández-Pajares M, Juan JM, Sanz J. 1999. New approaches in global ionospheric determination using ground GPS data. J Atmos Sol Terr Phys 61(16): 1237-1247. https://doi.org/10.1016/S13646826(99)00054-1.

Hernández-Pajares M, Juan JM, Sanz J. 2006. Medium-scale traveling ionospheric disturbances affecting GPS measurements: Spatial and temporal analysis. J Geophys Res Space Phys 111:A7. https://doi.org/10.1029/2005JA011474.

Hernández-Pajares M, Juan JM, Sanz J, Aragón-Ànge À, García-Rigo A, Salazar D, Escudero M. 2011. The ionosphere: effects, GPS modeling and the benefits for space geodetic techniques. J Geod 85(12): 887-907. https://doi.org/10.1007/ s00190-011-0508-5.

Hernández-Pajares M, Juan JM, Sanz J, Aragón-Àngel A. 2012. Propagation of medium scale traveling ionospheric disturbances at different latitudes and solar cycle conditions. Radio Sci 47: RS0K05. https://doi.org/10.1029/2011RS004951. 
Hernández-Pajares M, Lyu H, Garcia-Fernandez M, Orus-Perez R. 2020. A new way of improving global ionospheric maps by ionospheric tomography: consistent combination of multi-GNSS and multi-space geodetic dual-frequency measurements gathered from vessel-, LEO-and ground-based receivers. J Geod 94(8): 1-16. https://doi.org/10.1007/s00190-020-01397-1.

Hines C. 1972. Gravity waves in the atmosphere. Nature 239: 73-78. https://doi.org/10.1038/239073a0.

Huang X, Reinisch BW. 1996. Vertical electron density profiles from Digisonde ionograms: The average representative profile. Ann Geophys XXXIX(4): 751-756. https://doi.org/10.4401/ag4010 .

Huang X, Reinisch BW. 2001. Vertical electron content from ionograms in real time. Radio Sci 36(2): 335-342. https://doi.org/ 10.1029/1999RS002409.

Ibanga JI, Akpan AE, George NJ, Ekanem AM, George AM. 2018. Unusual ionospheric variations before the strong Auckland Islands, New Zealand earthquake of 30th September, 2007. NRIAG J Astron Geophys 7: 149-154. https://doi.org/10.1016/j. nrjag.2017.12.007.

Jin SG, Jin R, Li JH. 2014. Pattern and evolution of seismoionospheric disturbances following the 2011 Tohoku earthquakes from GPS observations. J Geophys Res Space Phys 119(9): 7914-7927. https://doi.org/10.1002/2014JA019825.

Jin S, Jin R, Liu X. 2019. GNSS atmospheric seismology: Theory, observations and modeling. Springer, Singapore. pp. 315. https://doi.org/10.1007/978-981-10-3178-6_9.

Jin SG, Occhipinti G, Jin R. 2015. GNSS ionospheric seismology: Recent observations evidences and characteristics. Earth Sci Rev 147: 54-64. https://doi.org/10.1016/j.earscirev.2015.05.003.

Jin SG, Zhu W, Afraimovich E. 2010. Co-seismic ionospheric and deformation signals on the 2008 magnitude 8.0 Wenchuan Earthquake from GPS observations. Int J Remote Sens 31(13): 3535-3543. https://doi.org/10.1080/01431161003727739.

Ke F, Wang Y, Wang X, Qian H, Shi C. 2016. Statistical analysis of seismo-ionospheric anomalies related to Ms $>5.0$ earthquakes in China by GPS TEC. J Seismol 20: 137-149. https://doi.org/ 10.1007/s10950-015-9516-x.

Komjathy A, Galvan DA, Stephens P, Butala M, Akopian V, Wilson B, Verkhoglyadova O, Mannucci AJ, Hickey M. 2012. Detecting ionospheric TEC perturbations caused by natural hazards using a global network of GPS receivers: The Tohoku case study. Earth Planet Space 64: 1287-1294. https://doi.org/ 10.5047/eps.2012.08.003.

Krypiak-Gregorczyk A, Wielgosz P. 2018. Carrier phase bias estimation of geometry-free linear combination of GNSS signals for ionospheric TEC modeling. GPS Solut 22: 45. https://doi.org/ 10.1007/s10291-018-0711-4.

Kuo FS, Chou SY, Shan SJ. 1998. Comparison of topside and bottomside irregularities in equatorial $\mathrm{F}$ region ionosphere. J Geophys Res 103(A2): 2193-2199. https://doi.org/10.1029/ 97JA02586.

Le H, Liu JY, Liu L. 2011. A statistical analysis of ionospheric anomalies before 736 M6.0+ earthquakes during 2002-2010. J Geophys Res 116: A02303. https://doi.org/10.1029/2010ja015781.

Li M, Parrot M. 2013. Statistical analysis of an ionospheric parameter as a base for earthquake prediction. J Geophys Res Space Phys AGU/Wiley 118: 3731-3739. https://doi.org/10.1002/ jgra.50313.

Liu JY, Chuo YJ, Shan SJ, Tsai YB, Chen YI, Pulinets SA, Yu SB. 2004. Pre-earthquake ionospheric anomalies registered by continuous GPS TEC measurements. Ann Geophys 22(5): 1585-1593. https://doi.org/10.5194/angeo-22-1585-2004.
Liu JY, Chen YI, Chuo YJ, Chen CS. 2006a. A statistical investigation of pre earthquake ionospheric anomaly. J Geophys Res 111: A05304. https://doi.org/10.1029/2005JA011333.

Liu JY, Tsai YB, Ma KF, Chen YI, Tsai HF, Lin CH, Kamogawa M, Lee CP. 2006b. Ionospheric GPS total electron content (TEC) disturbances triggered by the 26 December 2004 Indian Ocean Tsunami. J Geophys Res Space Phys 111(A5): https://doi.org/ 10.1029/2005JA011200.

Liu JY, Sun YY. 2011. Seismo-traveling ionospheric disturbances of ionograms observed during the $2011 M_{w} 9.0$ Tohoku Earthquake. Earth Planet Space 63: 70. https://doi.org/10.5047/eps.2011. 05.017.

Liu JY, Chen CH, Lin CH, Tsai HF, Chen CH, Kamogawa M. 2011. Ionospheric disturbances triggered by the 11 March 2011 M9.0 Tohoku earthquake (1978-2012). J Geophys Res Space Phys 116 (A6): A06319. https://doi.org/10.1029/2011JA016761.

Liu (Tiger) JY, Hattori K, Chen YI. 2018. Application of Total Electron Content derived from the Global Navigation Satellite System for Detecting Earthquake PrecursorsIn: Pre-Earthquake Processes, Ouzounov D, Pulinets S, Hattori K, Taylor P (Eds.), American Geophysical Union (AGU)/John Wiley \& Sons Inc. https://doi.org/10.1002/9781119156949.ch17.

Liu JY, Lin CY, Chen YI, Wu TR, Chung MJ, Liu TC, Tsai YL, Chang LC, Chao CK, Ouzounov DP, Hattori K. 2020. The source detection of September 28, 2018, Sulawesi tsunami by using ionospheric GNSS total electron content disturbance. Geosci Lett 7: 11. https://doi.org/10.1186/s40562-020-00160-w.

Liu C, Guan Y, Zheng X, Zhang A, Diego P, Sun Y. 2019. The technology of space plasma in-situ measurement on the China Seismo-Electromagnetic Satellite. Sci China Technol Sci 62: 829-838. https://doi.org/10.1007/s11431-018-9345-8.

Lognonné P, Artru J, Garcia R, Crespon F, Dučić V, Jeansou E, Occhipinti G, Helbert J, Moreaux G, Godet P. 2006. Ground-based GPS imaging of ionospheric postseismic signal. Planet Space Sci 54: 528-540. https://doi.org/10.1016/j.pss.2005.10.021.

Luo X, Xiong C, Gu S, Lou Y, Stolle C, Wan X, Liu K, Song W. 2019. Geomagnetically conjugate observations of equatorial plasma irregularities from Swarm constellation and ground-based GPS stations. J Geophys Res Space Phys 124: 3650-3665. https://doi.org/10.1029/2019JA026515.

Marchetti D, Akhoondzadeh M. 2018. Analysis of Swarm satellites data showing seismo-ionospheric anomalies around the time of the strong Mexico $\left(M_{w}=8.2\right)$ earthquake of 08 September 2017. $A d v$ Space Res 62(3): 614-623. https://doi.org/10.1016/j.asr.2018. 04.043.

Marchetti D, De Santis A, Jin S, Campuzano SA, Cianchini G, Piscini A. 2020a. Co-seismic magnetic field perturbations detected by Swarm Three-Satellite Constellation. Remote Sens 12: 1166. https://doi.org/10.3390/rs12071166.

Marchetti D, Santis AD, Shen X, Campuzano S, Perrone L, et al. 2020b. Possible Lithosphere-Atmosphere-Ionosphere Coupling effects prior to the $2018 M_{w}=7.5$ Indonesia earthquake from seismic, atmospheric and ionospheric data. J Asian Earth Sci 188: 104097. https://doi.org/10.1016/j.jseaes.2019.104097.

Maruyama T, Tsugawa T, Kato H, Saito A, Otsuka Y, Nishioka M. 2011. Ionospheric multiple stratifications and irregularities induced by the 2011 off the Pacific Coast of Tohoku Earthquake. Earth Planet Space 63(7): 65. https://doi.org/10.5047/eps.2011.06.008.

Occhipinti G, Rolland L, Lognonné P, Watada S. 2013. From Sumatra 2004 to Tohoku-Oki 2011: The systematic GPS detection of the ionospheric signature induced by tsunamigenic earthquakes. J Geophys Res Space Phys 118(6): 3626-3636. https://doi.org/ 10.1002/jgra.50322. 
Occhipinti G, Aden-Antoniow F, Bablet A, Molinie JP, Farges T. 2018. Surface waves magnitude estimation from ionospheric signature of Rayleigh waves measured by Doppler sounder and OTH radar. Nature Sci Rep 8: 1555. https://doi.org/10.1038/ s41598-018-19305-1.

Ouzounov D, Pulinets S, Hattori K, Taylor P (Eds). 2018. PreEarthquake Processes: A Multi-disciplinary Approach to Earthquake Prediction Studies. AGU. John Wiley \& Sons Inc. pp. 385. https://doi.org/10.1002/9781119156949.

Parrot M, Li M. 2018. Statistical analysis of the ionospheric density recorded by the DEMETER satellite during seismic activity, in: Pre-Earthquake Processes: A Multidisciplinary Approach to Earthquake Prediction Studies. Ouzounov D, Pulinets S, Hattori K, Taylor P, (Eds.) John Wiley \& Sons - American Geophysical Union (AGU), Hoboken. pp. 319-328. https://doi.org/10.1002/ 9781119156949.ch18

Perevalova NP, Sankov VA, Astafyeva EI, Zhupityaeva AS. 2014. Threshold magnitude for ionospheric TEC response to earthquakes. J Atmos Sol Terr Phys 108: 77-90. https://doi.org/ 10.1016/j.jastp.2013.12.014.

Píša D, Parrot M, Santolík O. 2011. Ionospheric density variations recorded before the $2010 M_{w} 8.8$ earthquake in Chile. $J$ Geophys Res Space Phys AGU/Wiley 116: A08309. https://doi.org/10.1029/ 2011JA016611.

Pulinets SA, Boyarchuk KA, Hegai VV, Kim VP, Lomonosov AM. 2000. Quasielectrostatic Model of atmosphere-thermosphere-ionosphere coupling. Adv Space Res 26(8): 1209-1218. https://doi.org/ 10.1016/S0273-1177(99)01223-5.

Pulinets S, Davidenko D. 2014. Ionospheric precursors of earthquakes and Global Electric Circuit. Adv Space Res 53: 709-723. https://doi.org/10.1016/j.asr.2013.12.035.

Pulinets S, Ouzounov D. 2018. The possibility of earthquake forecasting: Learning from nature. IOP Publishing, $168 \mathrm{pp}$. https://iopscience.iop.org/book/978-0-7503-1248-6.

Ravanelli M, Occhipinti G, Savastano G, Komjathy A, Shume EB, Crespi M. 2021. GNSS total variometric approach: first demonstration of a tool for real-time tsunami genesis estimation. Sci Rep 11: 3114. https://doi.org/10.1038/s41598-021-82532-6.

Reddy CD, Shrivastava MN, Seemala GK, González G, Baez JC. 2017. Ionospheric plasma response to $M_{w} 8.3$ Chile Illapel Earthquake on September 16, 2015. In: The Chile-2015 (Illapel) Earthquake and Tsunami. Braitenberg C, Rabinovich AB (Eds.), Springer, Cham, Switzerland. pp. 145-155. https://doi.org/10.1007/ 978-3-319-57822-4_12.

Rolland LM, Occhipinti G, Lognonné P, Loevenbruck A. 2010. Ionospheric gravity waves detected offshore Hawaii after tsunamis. Geophys Res Lett 37(17): https://doi.org/10.1029/2010GL044479.

Rolland LM, Lognonné P, Astafyeva E, Kherani EA, Kobayashi N, Mann M, Munekane H. 2011. The resonant response of the ionosphere imaged after the 2011 off the Pacific coast of Tohoku Earthquake. Earth Planet Space 63(7): 853-857. https://doi.org/ 10.5047/eps.2011.06.020.

Roma-Dollase D, Hernández-Pajares M, Krankowski A, Kotulak K, Ghoddousi-Fard R, et al. 2018. Consistency of seven different GNSS global ionospheric mapping techniques during one solar cycle. J Geod 92(6): 691-706. https://doi.org/10.1007/s00190-017-1088-9.

Ryu K, Lee E, Chae JS, Parrot M, Pulinets S. 2014. Seismoionospheric coupling appearing as equatorial electron density enhancements observed via DEMETER electron density measurements. J Geophys Res Space Phys 119: 8524-8542. https://doi.org/ 10.1002/2014JA020284.

Savastano G, Komjathy A, Verkhoglyadova O, Mazzoni A, Crespi M, Wei Y, Mannucci AJ. 2017. Real-time detection of tsunami ionospheric disturbances with a stand-alone GNSS receiver: a preliminary feasibility demonstration. Sci Rep 7: 46607. https://doi. org/10.1038/srep46607.

Schmidt M. 2001. Grundprinzipien der Wavelet-Analyse und Anwendungen in der Geodäsie. Habilitationsschrift, Shaker Verlag, Aachen. ISBN 978-3-8265-8872-3.

Stanica DA, Stanica D, Błeôcki J, Ernst T, Jóźwiak W, Słomiński J. 2018. Pre-seismic geomagnetic and ionosphere signatures related to the $M_{w} 5.7$ earthquake occurred in Vrancea zone on September 24, 2016. Acta Geophys 66: 167-177. https://doi.org/10.1007/ s11600-018-0115-4.

Su YC, Liu JY, Chen SP, Tsai HF, Chen MQ. 2013. Temporal and spatial precursors in ionospheric total electron content of the 16 October $1999 M_{w} 7.1$ Hector Mine earthquake. J Geophys Res Space Phys 118: 6511-6517. https://doi.org/10.1002/jgra. 50586.

Sun YY. 2019. GNSS brings us back on the ground from ionosphere. Geosci Lett 6: 14. https://doi.org/10.1186/s40562-019-0144-0.

Tsugawa T, Saito A, Otsuka Y, Nishioka M, Maruyama T, Kato H, Nagatsuma T, Murata KT. 2011. Ionospheric disturbances detected by GPS total electron content observation after the 2011 off the Pacific coast of Tohoku Earthquake. Earth Planet Space 63(7): 875-879. https://doi.org/10.5047/eps.2011.06.035.

Tulasi Ram S, Sunil PS, Ravi Kumar M, Su S-Y, Tsai LC, Liu CH. 2017. Coseismic traveling ionospheric disturbances during the $M_{w}$ 7.8 Gorkha, Nepal, Earthquake on 25 April 2015 from ground and spaceborne observations. J Geophys Res Space Phys 122: 10669 10685. https://doi.org/10.1002/2017JA023860.

Venkatraman S, Heelis R. 2000. Interhemispheric plasma flows in the equatorial topside ionosphere. J Geophys Res 105(A8): 18457 18464. https://doi.org/10.1029/2000JA000012.

Yang YM, Meng X, Komjathy A, Verkholyadova O, Langley RB, Tsurutani BT, Mannucci AJ. 2014. Tohoku-Oki earthquake caused major ionospheric disturbances at $450 \mathrm{~km}$ altitude over Alaska. Radio Sci 49: 1206-1213. https://doi.org/10.1002/2014RS005580.

Yang H, Monte-Moreno E, Hernández-Pajares M. 2017. Multi-TID detection and characterization in a dense Global Navigation Satellite System receiver network. J Geophys Res Space Phys 122: 9554-9575. https://doi.org/10.1002/2017JA023988.

Yang H, Monte Moreno E, Hernández-Pajares M. 2019. ADDTID: An alternative tool for studying earthquake/tsunami signatures in the ionosphere. Case of the 2011 Tohoku earthquake. Remote Sens 11(16): 1894. https://doi.org/10.3390/rs11161894.

Zhang X, Shen X, Parrot M, Zeren Z, Ouyang X, Liu J, Qian J, Zhao S, Miao Y. 2012. Phenomena of electrostatic perturbations before strong earthquakes (2005-2010) observed on DEMETER. Nat Hazards Earth Syst Sci 12: 75-83. https://doi.org/10.5194/nhess12-75-2012.

Zhu K, Li K, Mengxuan F, Chi C, Yu Z. 2019. Precursor analysis associated with the Ecuador earthquake using Swarm A and C satellite magnetic data based on PCA. IEEE Access 7: $93927-$ 93936. https://doi.org/10.1109/ACCESS.2019.2928015.

Cite this article as: Jarmołowski W, Belehaki A, Hernández Pajares M, Schmidt M, Goss A, et al. 2021. Combining Swarm Langmuir probe observations, LEO-POD-based and ground-based GNSS receivers and ionosondes for prompt detection of ionospheric earthquake and tsunami signatures: case study of 2015 Chile-Illapel event. J. Space Weather Space Clim. 11, 58. https://doi.org/10.1051/swsc/2021042. 